\title{
Roles of Integrins in Gastrointestinal Cancer Metastasis
}

\author{
Sicong Hou ${ }^{1 * t}$, Jiaxin Wang ${ }^{2 \dagger}$, Wenqian $\mathrm{Li}^{2 \dagger}$, Xin $\mathrm{HaO}^{2}$ and Qinglei Hang ${ }^{3 *}$ \\ ${ }^{1}$ Department of Gastroenterology, Affiliated Hospital of Yangzhou University, Yangzhou University, Yangzhou, China, \\ ${ }^{2}$ Department of Clinical Medicine, Medical College, Yangzhou University, Yangzhou, China, ${ }^{3}$ Department of Experimental \\ Radiation Oncology, The University of Texas MD Anderson Cancer Center, Houston, TX, United States
}

OPEN ACCESS

Edited by:

Prabhat Purbey,

University of California, Los Angeles,

United States

Reviewed by:

Helena Soares,

Fac. Ciências Universidade de Lisboa,

Portugal

Xiuwei Yang,

University of Kentucky, United States

*Correspondence:

Sicong Hou

shou@yzu.edu.cn

Qinglei Hang

hql219@hotmail.com

${ }^{t}$ These authors have contributed equally to this work

Specialty section: This article was submitted to

Cellular Biochemistry,

a section of the journal

Frontiers in Molecular Biosciences

Received: 12 May 2021 Accepted: 08 October 2021

Published: 15 November 2021

Citation:

Hou S, Wang J, Li W, Hao X and Hang Q (2021) Roles of Integrins in Gastrointestinal Cancer Metastasis.

Front. Mol. Biosci. 8:708779.

doi: $10.3389 /$ fmolb.2021.708779
Integrins are a large family of heterodimeric transmembrane receptors which mediate cell adhesion and transmit signals to the cell interior. The mechanistic roles of integrins have long been an enigma in cancer, given its complexity in regulating different cellular behaviors. Recently, however, increasing research is providing new insights into its function and the underlying mechanisms, which collectively include the influences of altered integrin expression on the aberrant signaling pathways and cancer progression. Many studies have also demonstrated the potentiality of integrins as therapeutic targets in cancer treatment. In this review, we have summarized these recent reports and put a particular emphasis on the dysregulated expression of integrins and how they regulate related signaling pathways to facilitate the metastatic progression of gastrointestinal cancer, including gastric cancer (GC) and colorectal cancer (CRC), which will address the crucial roles of integrins in gastrointestinal cancer.

Keywords: integrin, EMT, transcription factors, cell signalings, gastric cancer, colorectal cancer

\section{INTRODUCTION}

In the past decades, cancer incidence and mortality have been rapidly growing worldwide. According to the statistics in 2020 from the American Cancer Society, in both sexes combined, gastric cancer (GC) was the fifth most commonly diagnosed cancer and the fourth leading cause of cancer related death; colorectal cancer (CRC) ranked third in terms of incidence but second in terms of mortality (Sung et al., 2021). Metastasis is the leading cause of gastrointestinal cancer-related death, considered as the most important biological feature of malignant tumors (Guan, 2015). Although increasing efforts have been made to clarify the underlying molecular mechanisms involved in GC and CRC metastatic progression, it is still one of the biggest challenges due to its complexity. Therefore, identifying specific genes governing the metastasis of gastrointestinal cancers will potentially contribute to elucidating mechanisms and discovering early diagnostic biomarkers as well as novel therapeutic targets.

Integrins are a group of transmembrane proteins serve as cell-matrix adhesion receptors for transducing signals and modulating diverse biological processes. To date, $18 \alpha$ and $8 \beta$ subunits have been identified, which can directly form 24 known heterodimers, each $\alpha / \beta$ combination endows a binding specificity of extracellular domains for different ligands (Hynes, 2002). The subunits, usually around 1,000 ( $\alpha$ subunits) and 750 ( $\beta$ subunits) amino acid residues in length, include a membranespanning helix, an ectodomain, and a typically short and unstructured cytoplasmic tail, with flexible linker regions between them (Campbell and Humphries, 2011). Integrin activation can regulate their affinity for ligands binding via the conformational changes in the extracellular domain when its C-terminal cytoplasmic tails bind with the activated cytoplasmic proteins, are commonly termed "inside-out" signaling (Springer and Dustin, 2012). Activated integrins determine the downstream 
TABLE 1 | Aberrant expression of integrins in gastrointestinal cancer.

\begin{tabular}{|c|c|c|}
\hline $\begin{array}{l}\text { Individual } \\
\text { integrins }\end{array}$ & $\begin{array}{l}\text { Altered expression observed in } \\
\text { gastrointestinal cancers }\end{array}$ & Associated phenotypes \\
\hline$\alpha 1 \beta 1$ & $\mathrm{GC} \uparrow, \mathrm{CRC} \uparrow$ & $\begin{array}{l}\text { Increased peritoneal dissemination in GC Fukuda et al. (2012). Increased cell proliferation, } \\
\text { survival, and migration abilities in CRC Boudjadi et al. (2017). }\end{array}$ \\
\hline$\alpha 2 \beta 1$ & $\mathrm{GC} \uparrow, \mathrm{CRC} \uparrow$ & $\begin{array}{l}\text { Increased cell survival, adhesion, migration, and peritoneal dissemination in GC Lin M.-T. et al. } \\
\text { (2007), Chuang et al. (2018). Increased cell anoikis resistance, proliferation, adhesion, } \\
\text { metastasis, and stemness in CRC Bartolomé et al. (2014a), Guha et al. (2019), Wu et al., (2019). }\end{array}$ \\
\hline$\alpha 3 \beta 1$ & $\mathrm{GC} \uparrow, \mathrm{CRC} \uparrow$ & $\begin{array}{l}\text { Increased cell adhesion, invasion, and peritoneal dissemination in GC Saito et al. (2010), Chen } \\
\text { et al. (2015). Increased cell proliferation, migration, and invasion abilities in HCT-116 CRC cells } \\
\text { Tian et al. (2020). }\end{array}$ \\
\hline$\alpha 4 \beta 1$ & $\mathrm{GC} \downarrow, \mathrm{CRC} \uparrow$ & $\begin{array}{l}\text { Decreased cell invasion and metastatic abilities in GC Park et al. (2004). Increased } \\
\text { lymphangiogenesis and lymph node metastasis in CRC Lv et al. (2016). }\end{array}$ \\
\hline$\alpha 5 \beta 1$ & $\mathrm{GC} \uparrow, \mathrm{CRC} \uparrow$ & $\begin{array}{l}\text { Increased angiogenesis, lymph node metastasis, and vascular invasion in GC Ren et al. (2014). } \\
\text { Increased cell anoikis resistance and migration; decreased cell autophagy in CRC Guha et al. } \\
\text { (2019), Thongchot et al. (2020). }\end{array}$ \\
\hline$\alpha 6 \beta 4$ & $\mathrm{GC} \uparrow, \mathrm{CRC} \uparrow$ & $\begin{array}{l}\text { Increased cell metastasis in GC Gan et al. (2018). Increased cell proliferation, migration, and } \\
\text { invasion abilities; decreased cell anoikis in most CRC cells Beaulieu (2019). Increased cell } \\
\text { apoptosis in RKO CRC cells Bachelder et al. (1999). }\end{array}$ \\
\hline$\alpha 7 \beta 1$ & $\mathrm{GC} \uparrow, \mathrm{CRC} \uparrow / \downarrow$ & $\begin{array}{l}\text { Increased cell migration, invasion, adhesion, and peritoneal metastasis in GC Yan et al. (2019), } \\
\text { Zang et al. (2020). Upregulated } \alpha 7 \beta 1 \text { related with cell invasion and metastasis in CRC Liu et al. } \\
\text { (2018). Downregulated } \alpha 7 \beta 1 \text { increased cell proliferation and migration in CRC Li et al. (2018). }\end{array}$ \\
\hline$\alpha 8 \beta 1$ & $\mathrm{CRC} \downarrow$ & Increased cell anoikis susceptibility in CRC Benoit et al. (2010). \\
\hline$\alpha 9 \beta 1$ & $\mathrm{CRC} \uparrow$ & Increased cell proliferation, invasion, and metastatic abilities in CRC Ou et al. (2014). \\
\hline $\begin{array}{l}\alpha \vee \beta 3, \alpha \vee \beta 5, \\
\text { and } \alpha \vee \beta 6\end{array}$ & $\mathrm{GC} \uparrow, \mathrm{CRC} \uparrow$ & $\begin{array}{l}\text { Increased cell proliferation, migration, and perineural invasion (av subunit) McCarty (2008), } \\
\text { Waisberg et al. (2014), Wang et al. (2019). Increased cell proliferation and invasion abilities } \\
\text { ( } 35 \text { subunit) Shi et al. (2021). }\end{array}$ \\
\hline
\end{tabular}

$\uparrow$, increased; $\downarrow$, decreased.

signaling events, which highlight the importance of the composition of integrin adhesomes (Horton et al., 2016). Accumulating evidence has demonstrated that this "outsidein" signaling could be also regulated by the sophisticated networks of integrins and other membrane receptors, such as growth factor receptors, urokinase plasminogen activator receptor (uPAR), transforming growth factor- $\beta$ (TGF- $\beta$ ) receptor, etc. (Giancotti and Ruoslahti, 1999; Zaidel-Bar et al., 2007; Margadant and Sonnenberg, 2010; Kim et al., 2011; Cantor et al., 2015). Altered expression patterns and activities of integrins have been frequently detected in many types of cancers, which could further promote tumor metastasis via downstream signaling pathways (Hamidi and Ivaska, 2018).

The metastatic ability of cancer cells depends on their diverse interactions with surrounding extracellular matrix (ECM) ingredients in the microenvironment (Walker et al., 2018). Integrins are well-known to bind with different ligands such as leukocyte-specific ligands, collagens, laminins, vitronectin, and fibronectin; altered integrins have long been correlated with the metastatic cell behaviors by initiating aberrant cellular signaling (Ganguly et al., 2013). Many researchers have reported modified expression of integrins was frequently observed and participated in metastatic progression of gastrointestinal cancers by multiple mechanisms. Here, we systematically reviewed the integrins that express abnormally in gastrointestinal cancer and the potential mechanisms of certain integrins involved in the multi-steps programmed metastasis including epithelialmesenchymal transition (EMT), invasion, intravasation, circulation, extravasation and colonization. A deep understanding of integrins-mediated molecular mechanisms and current shortcomings during gastrointestinal cancer metastasis will be necessary for the development of diagnostic and therapeutic strategies against cancer.

\section{ALTERED EXPRESSION OF INTEGRINS IN GASTROINTESTINAL CANCER}

Aberrant expression of integrins often has been observed in gastrointestinal cancer and received much attention as its fundamental role in cancer malignancy, including uncontrolled proliferation, apoptosis, metastasis, etc. In this section, we first reviewed the altered expression of certain integrins and their involvement in GC and CRC progression (Table 1).

Given the importance of integrins in GC and CRC, the multiple mechanistic roles governing integrins expression were comprehensively discussed. In GC and CRC, the alterations in integrins expression are regulated at different levels, including transcriptional, post-transcriptional, translational, and posttranslational level, in which the transcriptional level is most researched. The transcriptional activities of integrin $\alpha 1, \alpha 6$, and $\beta 4$ are positively modulated by the binding of oncogenic $\mathrm{Myc}$ to the consensus sequence sites (E box) in the promoter motif of certain integrins in CRC (Ni et al., 2005; Boudjadi and Beaulieu, 2016; Boudjadi et al., 2016; Beaulieu, 2019). Notably, neo integrin $a 6$ is expressed under the form of integrin $a 6 \mathrm{~A}$ in CRC cells, where epithelial splicing regulatory protein 2 (ESPR2) 
TABLE 2 | Transcription factors involved in the regulation of integrin subunits in GC and CRC.

Individual integrin subunits

a1

a2

a3

a5

a6

a7

$\beta 1$

$\beta 3$

$\beta 4$

$\beta 6$
Related transcriptional regulation

Myc increases a1 transcriptional activity in CRC Boudjadi et al. (2016).

AP-1 increases a2 transcriptional activity in GC Lin M.-T. et al. (2007).

Ets and Sp family increase a3 transcriptional activity in GC Katabami et al. (2006).

HIF-1a decreases a5 transcriptional activity in GC Rohwer et al. (2008). PTHrP, ZEB2-SP1, Twist1 and AP-1

increase a 5 transcriptional activity in CRC Anderson et al. (2007), Nam et al. (2014), Nam et al. (2015).

Myc increase a6 transcriptional activity in CRC Beaulieu (2019).

RAS-responsive element binding protein 1 (RREB1) decreases a7 transcriptional activity in CRC Li et al. (2018). Forkhead box C1 (FOXC1) increases a7 transcriptional activity in CRC Liu et al. (2018).

RelB and nuclear receptor subfamily 4 group A member 1 (NR4A1)/p300/Sp increase $\beta 1$ transcriptional activity in CRC Hedrick et al. (2017), Zhou et al. (2018). Forkhead box O3 (FOXO3a) increases $\beta 1$ transcriptional activity in GC Hu et al. (2017). Homebox D3 (HOXD3) and homeobox B5 (HOXB5) increase $\beta 3$ transcriptional activity in CRC Yang et al. (2019), Feng et al. (2021).

Myc, zinc-finger with KRAB and SCAN domains 3 (ZKSCAN3), and FOSL1 increase $\beta 4$ transcriptional activity in CRC Yang et al. (2008), Beaulieu (2019), Li et al. (2019).

Ets proto-oncogene 1 (Ets 1) increase $\beta 6$ transcriptional activity in CRC Bates et al. (2005). is stimulated by Myc alternatively splices a6 (Groulx et al., 2018). The upregulated integrin $\alpha 1, \alpha 6 \mathrm{~A}$, and $\beta 4$ can further activate the RAS/mitogen-activated protein kinase kinase (MEK)/extracellular signal-regulated kinase (ERK) pathway and promote $\beta$-catenin signaling to enhance Myc expression, indicating a potential positive feedback loop for sustaining Myc and integrins activity (Boudjadi and Beaulieu, 2016). Furthermore, functional analysis showed that integrins also contain binding sites for Ets, specificity protein (Sp) family transcription factors (TFs) and activating protein-1 (AP-1) in CRC. Li et al. demonstrated that increased expression of integrin $\beta 4$ in CRC might be regulated by FOSL1 (FOS like 1), an AP-1 transcription factor subunit (Li et al., 2019). The enhanced integrin $\alpha 3 \beta 1$ and $\alpha 5 \beta 1$ in CRC can be attributed to their increased interaction with activated Ets family TFs, which was induced by the K-ras mediated Raf/MEK/mitogen-activated protein kinase (MAPK) signaling (Schramm et al., 2000). It is worth mentioning that the promoter activity of integrin a5 can be modulated by several other TFs in CRC, such as parathyroid hormone-related protein (PTHrP) (Anderson et al., 2007), zinc finger E-box binding homeobox 2 (ZEB2)-SP1 (Nam et al., 2014), Twist 1 and AP-1 (Nam et al., 2015); while in GC, it has been reported that integrin $\alpha 5 \beta 1$ is stimulated by the loss of hypoxiainducible factor 1a (HIF-1a), an oxygen-dependent transcriptional activator, which results in enhanced metastasis (Rohwer et al., 2008). Besides, Janouskova et al. identified that the reactivation of $\mathrm{p} 53$ by Nutlin-3a could specifically inhibit integrin a $5 \beta 1$ expression both at the transcriptional and protein level in colon cancer cells (Janouskova et al., 2013). The TFs involved in regulating individual integrin subunits expression in GC and CRC were summarized in Table 2. As we know, gene transcription is regulated by the interaction between TFs and epigenetic modification (e.g. DNA methylation and histone modifications); the abnormal promoter DNA methylation or histone modifications is another pivotal factor of gene transcription which has been extensively studied. Park et al. reported that the loss of integrin a4 expression was caused by DNA methylation-based transcriptional repression in gastric carcinogenesis (Park et al., 2004). Li et al. identified that hypomethylation of integrin $\beta 4$ promoter was negatively correlated with down-regulated $\beta 4$ expression in CRC ( $\mathrm{Li}$ et al., 2019). Ferraro et al. proved that three methylation at lysine 27 on histone 3 (H3K27me3), was regulated by enhancer of zeste homolog 2 (EZH2), which repressed integrin a2 expression (Ferraro et al., 2013; Ferraro et al., 2014a). However, the effect of other histone modifications, such as demethylation, acetylation or deacetylation, phosphorylation and ubiquitination, on the regulation of integrin expression in gastrointestinal cancer needs further investigation.

Moreover, the integrins expression is also post-transcriptionally controlled by microRNA (miRNA) in GC and CRC. As examples, miR-21 inhibits integrin $\beta 4$ expression in CRC (Ferraro et al., 2014b) and miR-30a suppresses integrin $\alpha 2$ expression in intestinal-type early gastric carcinogenesis (Min et al., 2020). However, the role of other regulatory factors (e.g. RNA-binding proteins, lncRNAs and circRNAs) in integrin mRNAs regulation at the post-transcriptional level has not been reported in GC and CRC. Of note, recent studies have revealed that the stability, splicing and nuclear export of mRNA were regulated by RNA modifications, especially the N6methyladenosine $\left(\mathrm{m}^{6} \mathrm{~A}\right)$ modification, which eventually regulates the mRNA translation (Jin et al., 2019; Li E. et al., 2020). For example, integrin $a 6$ has been proved to be regulated by m6A posttranscriptionally in bladder cancer development (Jin et al., 2019). Prospectively, further explorations of RNA modifications on integrins in gastrointestinal cancer are expected. For the translation level, Cantor et al. showed that the upregulated integrin $\beta 6$, which was modulated by eukaryotic translation initiation factor $4 \mathrm{E}$ (eIF4E), may initiate a cascade of downstream signaling promoting CRC metastasis (Cantor et al., 2015). Kline et al. illustrated that Src activation decreased integrin a 3 expression at the protein level, but not the mRNA level, in a MAPK-dependent manner in CRC (Kline et al., 2009). Finally, as we know that post-translational modifications (PTMs) are also critical mechanisms to increase proteomic diversity. Although increasing evidence indicated that integrins are regulated by several types of PTMs, including phosphorylation, glycosylation, ubiquitination, nitrosylation and acetylation (Goldfinger et al., 2003; Oxley et al., 2008; Lobert et al., 2010; Meves et al., 2011; Isaac et al., 2012; Hou 


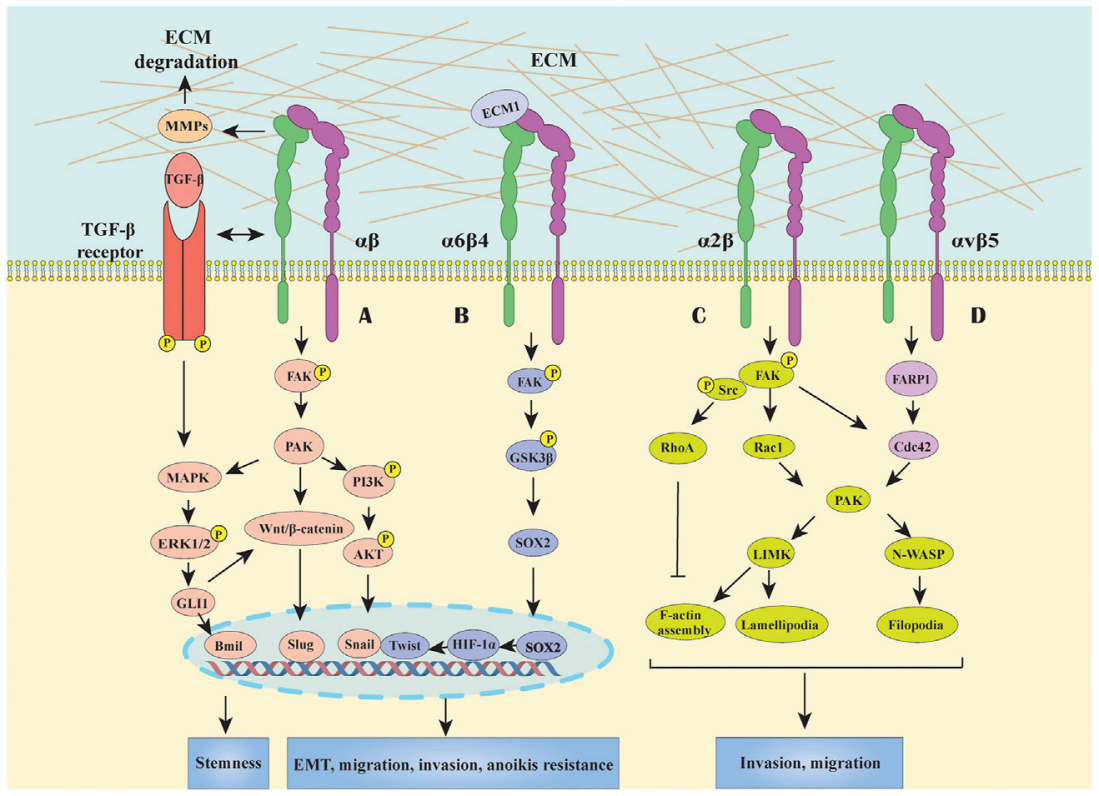

FIGURE 1 | Integrins mediated signal transduction pathways in GC. (A) Most integrins initiate FAK-generated signaling, including MAPK/ERK, PI3K/AKT and Wnt/ $\beta$-catenin pathways to participate in EMT, migration and invasion processes and acquire stemness and anoikis resistance. Besides, the crosstalk between TGF- $\beta$ and integrin signaling also can activate downstream effectors which cooperatively modulate EMT in a cross-regulation manner in GC. (B) Integrin $\alpha 6 \beta 4$ activate the FAK GSK3 $\beta$ signaling pathway, inducing the expression of transcription factor of SOX2, HIF-1 $\alpha$, Snail and Twist, to promote anoikis resistance and EMT activation. (C) Integrin a2 can stabilize F-actin, promote filopodia formation and lamellipodial protrusion by upregulating RhoA, Rac1, and Cdc42, thus facilitating GC cell migration. (D) Association of integrin $\alpha v \beta 5$ and FARP1 can facilitate cell motility by boosting the downstream molecule Cdc42 activity.

et al., 2016; Hang et al., 2017; Marsico et al., 2018; Gahmberg et al., 2019; Vega et al., 2020), how these PTMs regulate the stability and interactome of individual integrins are poorly understood, especially in gastrointestinal cancer. Therefore, more studies are needed to understand the dynamics of these PTMs, how they coordinately regulate integrins, the functional consequences of these PTMs and which is cancer metastasis related.

\section{ROLES OF INTEGRINS IN GASTRIC CANCER METASTASIS}

\section{Integrins and Epithelial-Mesenchymal Transition}

EMT has been considered as a critical component of the metastatic program changing cell morphology and enhancing cancer cell mobility and invasion abilities (Aiello and Kang, 2019). Substantial evidence showed that altered expression of integrins correlated with GC metastasis, and dysregulated integrin-mediated signaling pathways, such as focal adhesion kinase $(\mathrm{FAK}) / \mathrm{p} 21$-activated kinase $(\mathrm{PAK}), \mathrm{Wnt} / \beta$-catenin and FAK/glycogen synthase kinase-3 $\beta$ (GSK3 $\beta$ ), played essential roles in EMT process. Here, we systemically summarized the aberrant signaling events triggered by integrins during EMT in GC (Figure 1).

It is widely acknowledged that FAK is a major signal transduction downstream molecule of integrins which could affect EMT processes, including downregulation of cell-cell adhesion and overcome anoikis. As we know, FAK is comprised of three main domains: the N-terminal FERM domain, the central kinase domain and the C-terminal focal adhesion targeting (FAT) domain (carrying six phosphorylated tyrosine sites) (Kokkinos et al., 2007; Murphy et al., 2020). In normal circumstances, the interaction between the FERM and kinase domain maintains an autoinhibited state, and the autophosphorylation site Y397 is among the linker between them (Tapial Martínez et al., 2020). Once the cytoplasmic tail of the integrin $\beta$ subunit binds to the amino terminus of FAK, Y397 autophosphorylation converts the site into a high-affinity binding site for the SH2 domain of Src resulted in Src activation, which in turn phosphorylates other tyrosines of FAK, thus inducing the complete catalytic activity of FAK, consequently recruiting other signaling molecules to the focal adhesion sites and sustaining the signaling (Cooper et al., 2003; Tapial Martínez et al., 2020). The mechanisms of FAK in triggering EMT in GC are proposed to serve as the intersection of multiple signal pathways, including MAPK, phospoinositide 3-kinase (PI3K)/ AKT and Wnt/ $\beta$-catenin (Matsuoka et al., 2012; Dammann et al., 2014; Wang et al., 2019). Indeed, these integrins/FAK-mediated signalings in GC also contribute to overcoming apoptosis, which is a typical characteristic of the acquisition of mesenchymal phenotype. For instance, it has been shown that the interaction between integrin $\beta 4$ and extracellular matrix protein 1 (ECM1) could activate the $\beta 4 / F A K / G S K 3 \beta$ signaling pathway, then induced the expression of transcription factor 
SOX2 and HIF-1a, which eventually contribute to EMT (Gan et al., 2018) (Figure 1). Besides, enhanced PI3K/AKT, MAPK and $\mathrm{Wnt} / \beta$-catenin signals can stimulate anti-apoptotic proteins such as Snail, Twist, and etc., thus promoting anoikis resistance and EMT activation (Paoli et al., 2013; Peng et al., 2014) (Figure 1). Moreover, Integrin $\beta 1$ could associate with the carbohydraterecognizing domain (CRD) of Galectin-1 (Gal-1) secreted by activated cancer-associated fibroblasts (CAFs) via its extracellular carbohydrate structure, resulting in Glil expression which may further activating $\mathrm{Wnt} / \beta$-catenin signaling, and finally trigger the EMT process in GC cells (Elola et al., 2005; Chong et al., 2016; Zhang et al., 2020). In fact, not only Gal-1 upregulation, but also the alterations in glycosylation pattern of its binding protein (e.g. integrins) contribute to EMT process in GC (Kariya et al., 2017). For instance, $\mathrm{N}$-acetylglucosaminyltransferase III (GnTIII) and GnTV overexpression-modified glycosylation of integrin $\alpha 3 \beta 1$ and E-cadherin could induce EMT and cell invasion in GC cells, highlighting that targeting specific glycosylation might have potential in anti-cancer therapy; however, this needs further investigation (Zhao et al., 2006; Pinho et al., 2013).

In addition, TGF- $\beta$ as the most studied growth factor in EMT can regulate the expression and activation states of certain integrins and exert a synergistic effect with integrin signalings. For example, TGF- $\beta$-induced signaling activated integrin $\beta 1$ by phosphorylating its cytoplasmic tail in hepatocellular carcinoma invasion (Fransvea et al., 2009), while TGF- $\beta 1$ can increase the expression of integrin $\alpha 2 / \alpha 3$ and then facilitate GC cell spreading and migration (Lee et al., 2005), suggesting a tissue- and cellspecific regulatory manner which need to be further investigated. Besides, av-containing integrins can drive latent TGF- $\beta$ activation to sustain EMT by interacting with arginine-glycine-aspartic acid (RGD) motif on TGF- $\beta$ propeptide, a member of the inactive TGF- $\beta$ complexes (Ludbrook et al., 2003; Annes et al., 2004). In contrast, the effect of integrin $a v$ on EMT in GC have not been investigated. Moreover, the crosstalks between TGF- $\beta$ and integrin signalings can activate downstream effectors resulting in EMT, tumor invasion and metastasis (Mamuya and Duncan, 2012). For instance, the activated-integrin/FAK signal further mediate the activation of downstream molecules (e.g. MAPK, PI3K/AKT, and Ras); meanwhile, TGF- $\beta$ signaling can activate SMAD, MAPK, and PI3K signalings, which therefore modulate EMT in a cooperative manner in GC.

\section{Integrins in Migration and Invasion}

Cell migration and invasion are highly complex processes, in which integrins-mediated signalings control the organization of actin cytoskeleton via FAK/Src-activated small Rho GTPases, including RhoA, Rac, and Cdc42 (Huttenlocher and Horwitz, 2011) (Figure 1). As an example, integrin $\alpha 2$ can stabilize F-actin, promote filopodia formation and lamellipodial protrusion by upregulating Racl and $\mathrm{Cdc} 42$, thus facilitating GC cell migration (Chuang et al., 2018). Recent research reported that the association between integrin $\alpha v \beta 5$ and pleckstrin domain protein 1 (FARP1) facilitated cell motility and filopodium formation of GC cells by activating the downstream molecule Cdc42 (Hirano et al., 2020). In detail, the crystal structure of
FARP1 exhibited an autoinhibited conformation in which the RhoGTPase-binding site of the $\mathrm{DH}$ and the first $\mathrm{PH}$ (PH1) domain is primarily blocked by the second $\mathrm{PH}$ domain (PH2) (Kuo et al., 2018). Importantly, this autoinhibition is canceled once integrin $\alpha v \beta 5$ binds to FARP1, further promoting cell migration and invasion through $\mathrm{Cdc} 42 / \mathrm{PAK}$ signaling pathway (Chuang et al., 2018; Hirano et al., 2020). Considering the complex spatial structure of both integrin $\alpha v \beta 5$ and FARP1, the mechanism of how they regulate each other's activity needs further investigation.

Peritoneal metastasis (PM) appears to be one of the most frequent route of metastasis or recurrence in patients with GC and is usually associated with poor prognosis (Rau et al., 2020). Previous works defined integrins as crucial cell adhesion molecules involved in the adhesion of exfoliated GC cells to the mesothelium, which serve as an essential step in the initial PM process. It was reported that the interaction between integrin a3 $\beta 1$ and laminin-5 potentiated the cell adhesion to the peritoneum and the production of matrix metalloproteinase- 9 (MMP-9), which facilitated PM by the degradation of ECM in GC (Saito et al., 2010). Specifically, laminin-5, which was produced by mesothelial cells, could be recognized or modulated by integrin a $3 \beta 1$ via the following domains: the LG domains of a chain, C-terminal short stretch of $\beta$ chain and nearly C-terminal glutamic acid residue of $\gamma$ chain (Yamada and Sekiguchi, 2015). Moreover, integrin $\alpha 2 \beta 1$-mediated the cysteine-rich angiogenic inducer 61 (CYR61)/AP-1 cascade, could promote cell adhesion to the peritoneum (Lin M.-T. et al., 2007). In addition, the activated ERK/JNK signaling and upregulated integrin $\alpha 5$ and fibronectin expression, which is induced by the association of vascular endothelial growth factor A (VEGFA) with VEGF receptor 1 (VEGFR1) under hypoxic microenvironment, could promote PM in GC (Wang et al., 2020). Furthermore, integrin $\alpha v \beta 3$ was reported to promote the PM in GC cells, of which the potential $\alpha v \beta 3 /$ ERK/ GLI1 pathway-mediated maintenance role in stem cell-like phenotype of exfoliated cells was involved (Dong et al., 2019). A recent study showed the lipid phosphate phosphatase-related protein type 4 (LPPR4) could upregulate integrin a subunits (including $\alpha 1, \alpha 2, \alpha 5, \alpha 6$, and $\alpha 7$ ), but not $\beta$ subunits, expression via SP1 transcription factor; thus, activating the FAK/Src/AKT/ MMP2 signaling pathway, which eventually promoted the PM in GC cells (Zang et al., 2020). Overall, these findings emphasized the importance of integrins in PM, suggesting certain integrins may serve as a promising diagnostic marker and treatment strategy for GC patients with PM, and more clinical correlations are needed to validate these possibilities.

\section{Integrins in Intravasation, Circulation, Extravasation and Colonization}

Increasing evidence implicated integrins played key roles in the remaining metastatic steps since tumor cells enter the blood vessels, including intravasation, circulation and extravasation, leading to colonization at a distant site (Hamidi and Ivaska, 2018). However, there is limited research about the role of integrins in these steps in GC. It has been demonstrated that 
CYR61 can induced C-X-C chemokine receptors CXCR1/CXCR2 expression by activating integrin $\alpha v \beta 3 / \mathrm{Src} / \mathrm{PI} 3 \mathrm{~K} / \mathrm{AKT}$ pathway, thus exhibiting increased potency in interleukin-8 (IL-8) chemotaxis, transendothelial migration and intravasation in GC cells (Lin B.R. et al., 2007). In addition, integrin $\beta 4$ and its distinctive effects on regulation of cytoskeletal and hemidesmosomes have been well studied. Under physiological conditions, integrin $\beta 4$ forms the complex with plectin (PLEC), which can maintain filamin A (FLNA) and cytoskeleton stability, once the integrin $\beta 4$-PLEC interaction is disrupted, the disassociated PLEC binds to F-actin and damages the cytoskeleton network (Koster et al., 2003). In GC cells lacking transmembrane protein 268 (TMEM268), a novel protein involved in tumorigenesis, lead to increased ubiquitinmediated degradation of integrin $\beta 4$ and cytoskeleton remodeling, thus losing the possibility of circulating tumor cells (CTCs) adhere to vascular endothelium, extravasate into other organs, and eventually fail to form metastatic colonization (Hong et al., 2019). Accordingly, a recent study found that the immunostaining intensity of integrin $\beta 4$ in lymphovascular invasion (LVI) and perineural invasion (PNI) in GC was significantly higher than that in normal stomach, indicating $\beta 4$ may be a potential novel marker for detection and diagnose of LVI and PNI in GC patients (Li J. et al., 2020).

During the metastatic process, extravasation is a critical step for CTCs to form the pre-metastatic niche and its efficiency is largely dependent on the permeability and integrity of the vascular endothelium (Lambert et al., 2017). In many types of cancers, increased angiopoietin 2 (Ang2) accompanied by the decreased angiopoietin receptor Tie2 exhibit the predisposition to the integrin $\alpha 5 \beta 1$-Ang2 interaction, which has been implicated in compromised permeability through integrin $\beta 1$ signaling (Imanishi et al., 2007; Hakanpaa et al., 2015). Of note, the endothelial integrin a5 could also trans-interacted with neuropilin 2 (NRP2) on cancer cells, promoting the vascular extravasation in pancreatic adenocarcinoma mouse xenograft models (Cao et al., 2013). Although upregulated expression of integrin $\alpha 5 \beta 1$ correlates with increased metastasis and vascular invasion in GC as mentioned above, the mechanisms involved in its role in extravasation and metastasis are poorly understood and need further investigation.

\section{FUNCTIONS OF INTEGRINS IN COLORECTAL CANCER METASTASIS}

\section{Integrins and Epithelial-Mesenchymal Transition}

Abundant evidence show that EMT is associated with the invasive or metastatic phenotype in CRC (Vu and Datta, 2017). Integrins have long been known to regulate cell-cell and cell-ECM events and trigger the downstream signaling pathways, leading to malignancy. Among the multiple integrins, integrin av $\beta 6$ has been well studied about its role in EMT initiation and progression in CRC. Activated TGF- $\beta$ signaling plays essential role in the modulation of integrin $\alpha \mathrm{v} \beta 6$ level via promoting SMAD4 binding to its promoter motif, thus facilitating cell migration (Bandyopadhyay and Raghavan, 2009). Of note, integrin expression can also be regulated by the non-canonical pathway (SMAD independent manner) induced by TGF- $\beta$, for example, ERK/MAPK signal pathway is involved in the TGF- $\beta$-triggered integrin $\alpha v \beta 6$ transcription via Ets-1 (Callaway et al., 2006). In addition to TGF- $\beta$, interleukin-6 (IL-6) was reported to induce EMT by increasing integrin $\beta 6$ expression in CRC cells, during which the IL-6 receptor/STAT3 signaling pathway was involved (Sun and Shang, 2020). Interestingly, integrin $\alpha v \beta 6$ can mediate latent TGF- $\beta$ activation by directly interacting with the RGD sequence presented in the latency-associated protein (LAP), which require the latent TGF- $\beta$ binding protein-1 (LTBP-1) to localize, concentrate and fix the latent form of TGF- $\beta$ (Annes et al., 2004). Moreover, the integrin $\alpha v \beta 6$-mediated TGF- $\beta$ activation can further stimulate fibroblasts to secrete stromal cell-derived factor-1 (SDF-1), resulting in CRC invasion via the SDF-1/C-X-C chemokine receptor type 4 (CXCR4) axis (Peng et al., 2018). Therefore, upregulated integrin av $\beta 6$ could cooperate with TGF- $\beta$ to induce and sustain EMT process, providing a positive feedback loop to perpetuate EMT and rendering the tumor microenvironment more amenable to form the pre-metastasis niche (Figure 2). Given the importance of integrin $\alpha v \beta 6$ in EMT and metastasis, it is reasonable to speculate that $\alpha v \beta 6$ may be a potential marker of EMT as well as a novel therapeutic target for CRC in the near future.

In addition to integrin av $\beta 6$, other integrins can also contribute to EMT to accelerate migration in CRC. $\mathrm{Wu}$ et al. demonstrated that the interaction between integrin $\alpha 2 \beta 1$ and enriched collagen I could activate the PI3K/AKT signaling pathway to induce the EMT process through transcription factor snail activation in CRC cells (Wu et al., 2019) (Figure 2). Significantly, blocking integrin a $2 \beta 1$ efficiently suppressed the metastasis and combination of $\alpha 2 \beta 1$ inhibitor with chemotherapeutic agents exhibited a synergistic antitumor effect, revealing a potentially promising treatment approach for CRC treatment (Wu et al., 2019). Recently, increasing evidence highlighted that the expression of integrins in tumor budding (TB), a process that exhibits characteristics of partial EMT, may predict survival in patients with CRC. For instance, Zhou et al. observed that the interaction between integrin $\beta 1$ and laminin$5 \gamma 2$ promoted the TB via FAK and Yes-associated proteins (YAP) activation in CRC (Zhou et al., 2020). Slik et al. demonstrated that aberrant EMT-associated markers, including integrin $\beta 4$, E-cadherin and zonula occludens-1 (ZO-1), could be detected by multiplex immunohistochemistry in tumor buds of stage II CRC, highlighting the potential role of integrins in EMT-like phenotypes of TB (Slik et al., 2019). Moreover, transmembrane protease serine 4 (TMPRSS4) was reported to suppress E-cadherin expression, leading to EMT and invasiveness via stimulating integrin $a 5 \beta 1$ expression in CRC (Kim et al., 2010). Of note, several other integrins, such as integrin $\alpha v \beta 3$, $\alpha 6 \beta 4$, and $\beta 5$, have been demonstrated to play crucial roles in EMT of different types of cancer, including breast cancer, hepatocellular carcinoma and renal cell carcinoma (Bianchi et al., 2010; Knowles et al., 2013; Mori et al., 2015; Li et al., 2017; Kariya et al., 2021), the effect of these integrins on EMT in CRC need to be explored. In addition, how about the impact of 


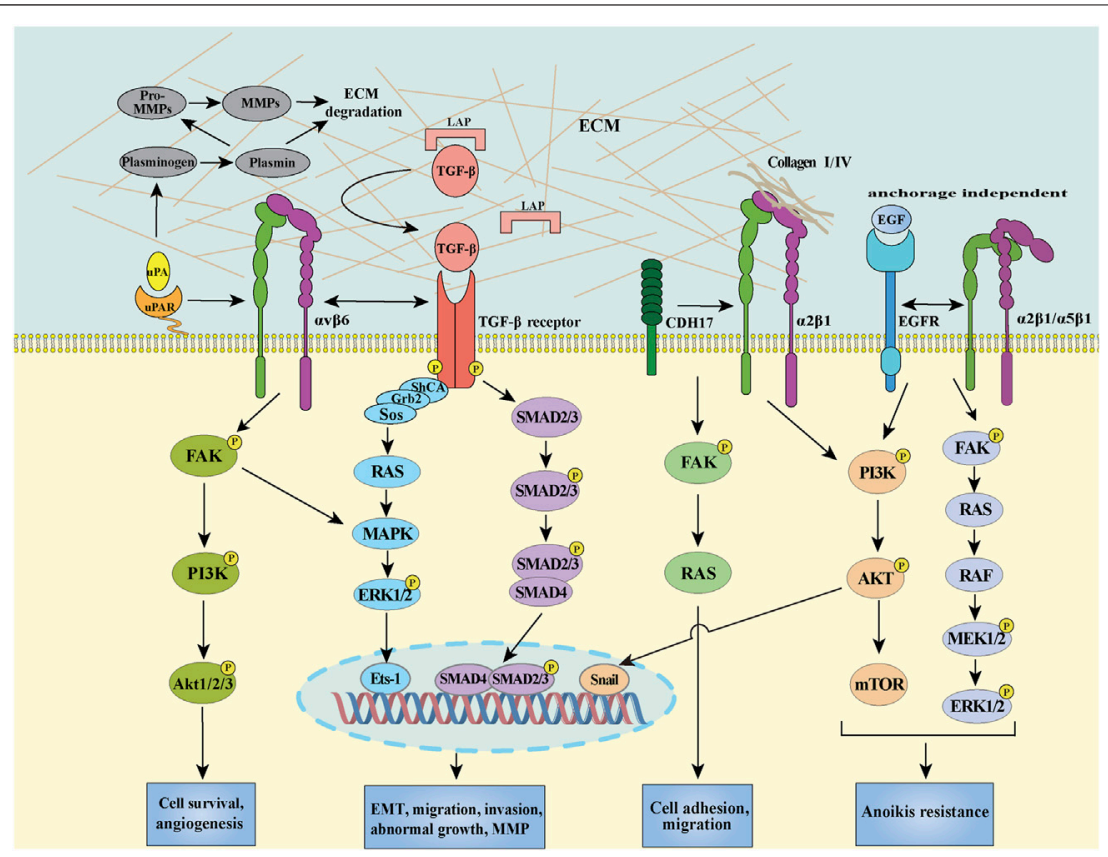

FIGURE 2 | Schema of integrin $\alpha \vee \beta 6 / T G F-\beta$ receptor/uPAR, integrin $\alpha 2 \beta 1 / \mathrm{CDH} 17$, integrin $\alpha 2 \beta 1$ (or $\alpha 5 \beta 1$ )/EGFR mediated signal transduction pathways in CRC. Integrin $\alpha \vee \beta 6$ separately interacts with uPAR and TGF- $\beta$ receptor, initiating intracellular signaling contributes to the activation of transcription factors, such as Ets- 1 and SMAD2/3/4 through the FAK/PI3K, RAS/ERK, and SMAD pathways. CDH17 provokes a conformational change in the $\beta 1$ subunit, activating the downstream FAK/RAS pathway to increase cell adhesion. The crosstalk between integrin $\alpha 2 \beta 1 / \alpha 5 \beta 1$ and EGFR can induce PI3K/AKT signaling to promote EMT through stimulating transcription factor snail in CRC cells. On the other hand, integrin $\alpha 2 \beta 1 / E G F R$ also can activate FAK/ERK and PI3K/AKT survival pathway resulting in anoikis resistance in the absence of ECM.

integrins on other EMT inducers, such as EGF, Wnt and Hedgehog (Hh), -mediated EMT, and especially how integrins crosstalk with the membrane receptors of these inducers as well as TGF- $\beta$ receptors are still unaddressed.

\section{Integrins in Migration and Invasion}

Integrin $\alpha v \beta 6$ is thought to regulate several metastatic phenotypes in CRC via diverse mechanisms (Cantor et al., 2015). uPAR is a GPI anchored protein, which lacks transmembrane and intracellular domains and requires cooperation with other transmembrane receptors to mediate signal transduction (Smith and Marshall, 2010). The crosstalk between integrin $\alpha v \beta 6$ and UPAR is implicated in the regulation of their downstream signalings upon urokinase (uPA) binding (Figure 2) (Smith and Marshall, 2010; Sowmya et al., 2014). Mechanistically, integrin av could interact with the outer surface of UPAR domain III region, which provides structural support and/or shield the DI-DII linker region of UPAR from the cleavage by pericellular proteolysis, thus promoting the persistence of the active binding conformation of uPA on cell surface (Cantor et al., 2015). The increased association between integrin $\alpha v \beta 6$ and $\mathrm{uPA} / \mathrm{uPAR}$ could further induce MMP9 secretion, thus prompting the degradation of extensive ECM components in a MAPK/extracellular signal-regulated kinase (MEK1) dependent manner (Gao et al., 2014; Cantor et al., 2015). In parallel to the uPAR signaling, TGF- $\beta$ could also be activated by integrin $\alpha v \beta 6$ as mentioned above, highlighting the importance of integrin $\alpha v \beta 6$ during multiple metastasis steps.
Furthermore, upregulated integrin av $\beta 6$ was involved in IL-8promoted migration in CRC (Sun et al., 2014). Given that integrin $\alpha v \beta 6$ provides a structural foundation to facilitate the recruitment of TGF- $\beta$, IL- 8 and critical components of the PA cascade, a pericellular interactome has been proved to play critical roles in concentrating key metastasis-related proteins and activating downstream signaling axis (Figure 2). In addition to integrin $\alpha v \beta 6$, integrin $\beta 1-\mathrm{uPAR}$ complex could also enhance the CRC cell migration and invasion, as well as ECM degradation by activating ERK/MAPK pathway and increasing MMP-2/MMP-9 expression (Ahmed et al., 2003).

The extensive molecular crosstalk between integrins and receptor tyrosine kinases (RTK) makes the metastasis mechanism more complicated. Guha et al. found that integrin $\alpha 2 \beta 1 / \alpha 5 \beta 1$ could colocalize with EGFR on cell surface in the anoikis-resistant CRC cells which was involved in the migration of CRC cells from the primary site to newly distant site(s) and could grant the cells with stem cell-like properties; the integrin $\alpha 2 \beta 1 / \alpha 5 \beta 1-E G F R$ complex can activate the ERK/AKT-mediated survival pathway and inhibit caspase-3 activation and consequently inducing anoikis resistance in the absence of ECM (Guha et al., 2019). Additionally, integrin a6 $\beta 4$ could also modulate the metastatic process of CRC via cooperating with RTKs and activating oncogenic signaling. This crosstalk can phosphorylate the $\beta 4$ cytoplasmic tail via stimulating the Src family kinases (SFKs), triggering the ERK/PI3K pathway to regulate specific $\mathrm{TFs}$ and eventually facilitating the cell 
migration. As mentioned above, integrin a6 subunit can regulate the downstream effector $\mathrm{Myc}$, which appears to promote the transcription of integrin $\alpha 6 \beta 4$ via the $\mathrm{Wnt} / \beta$-catenin pathway (Beaulieu, 2019). Of note, the role of certain integrin in CRC cell migration remains controversial. For instance, it has been shown that the morphological response of CRC cells on laminin-10, which contributes to cell adhesion and spreading, is mediated by the synergistic action of EGFR in an integrin a $3 \beta 1$ dependent manner (Pouliot et al., 2000). However, Hashida et al. demonstrated that integrin a $3 \beta 1$ could form complexes with MRP-1/CD9 and KAI1/CD82, which was negatively correlated with CRC progresses (Hashida et al., 2002). Thus, the exact role of integrin $a 3 \beta 1$ in CRC cells has not been fully understood and further investigations are needed to address whether the function of integrin $\alpha 3 \beta 1$ in CRC is cell line dependent through specific binding partners.

Moreover, integrins could promote CRC migration and invasion by interacting with other proteins, such as cadherin17 (CDH17), CYR61, glucose-regulated protein 78 (GRP78), and periostin (PN). In detail, Bartolomé et al. demonstrated that the integrin $\alpha 2 \beta 1$ expression was highly associated with liver metastasis in CRC, especially in the patients with latestage metastasis, mechanistically, $\mathrm{CDH} 17$ was involved in binding with and activate integrin $\alpha 2 \beta 1$ through its RGD motif and leading a conformation change of integrin $\beta 1$, which activate the MAPK signaling pathway to induce CRC cell adhesion, in the meanwhile, CDH17-activated integrin $\alpha 2 \beta 1$ can interact with collagen IV in a RGD independent manner, which further enhances the cell adhesion to collagen IV and thus increasing cell proliferation ability (Bartolomé et al., 2014a; Bartolomé et al., 2014b) (Figure 2). Monnier, et al. showed that integrin $\alpha v \beta 5$ can cooperate with matricellular protein CYR61 to enhance CRC cell invasion and metastasis in the presence of preirradiated stroma (Monnier et al., 2008). Furthermore, Li et al. illustrated that the interplay between integrin $\beta 1$ and GRP78 could directly facilitate CRC cell migration and invasion (Li et al., 2013). Recently, Thongchot, et al. showed that PN could control the autophagy-regulated cell migration through binding to integrin $\alpha 5 \beta 1$ or $\alpha 6 \beta 4$ and sequentially activating the AKT pathway (Thongchot et al., 2020). In addition to these outer membrane regulations, the inner membrane regulation was also involved. For example, Beaulieu identified that enhanced integrin a6 34 can preferentially interact with cytoskeletal keratins of hemidesmosomes in the cytoplasm, resulting in the acquisition of a more migratory and anoikis-resistant phenotype in CRC cell (Beaulieu, 2019). Although the importance of these integrin-associated complexes has been highlighted in CRC cell migration and invasion, the detailed mechanisms of how they interplay with each other, especially in different pathological conditions, are still unclear, which need follow-up investigations.

Integrins in Extravasation and Colonization Extravasation is a process of CTCs arresting, adhering, and passing through vascular endothelium after circulation (Azevedo et al., 2015). It has been demonstrated that the
P-selectin binding-mediated activation of integrin $\alpha 5 \beta 1$ can promote cell adhesion to endothelium via the PI3K and p38 MAPK signaling pathways in CRC cells (Reyes-Reyes et al., 2006). In addition to integrin $\alpha 5 \beta 1$, the integrin $\alpha v \beta 5$ could be activated by autocrine TGF $\beta$-induced in CRC cells, enhancing integrin av $\beta 5 /$ Src signaling and then inducing the dissociation of VEcadherin junctions between endothelium cells which facilitated extravasation (Ma et al., 2008). Furthermore, integrin $\alpha v \beta 5$ could also bind to fibronectin and promote the adhesion of CRC cells to endothelium; however, it was not involved in the following metastasis step of transendothelial migration into the liver parenchyma (Enns et al., 2005). Moreover, the adhesive and invasive of colorectal CTCs within the hepatic microvasculature by intravital fluorescence microscopy showed that integrin $\alpha 2, \alpha 6, \beta 1$, and $\beta 4$ mediate the extravasation of CRC cells into liver (Enns et al., 2004). Functional blocking of integrin $\alpha 2, \alpha 6$, and $\beta 4$ in HT29 CRC cells could inhibit the extravasation process (Robertson et al., 2009), further highlighting the importance of different integrins during the extravasation of CRC cell. However, the detailed molecular mechanism on how these integrins-mediated extravasation, especially the precise balance between the dissociation and adhesion, remains unclear. For the colonization process, the integrin a6/ E-cadherin supramolecular complex was reported to strengthen their binding ability to hepatic angiopoietin-like 6 , driving the liver homing and colonization of CRC cells (Marchiò et al., 2012). However, the role of integrin in intravasation and circulation during metastasis in CRC is still unclear and needs more investigation. Given that high expression of these integrins are usually associated with poor survival in metastatic CRC, more studies should focus on the specific clinical significance of the indicate integrins as biomarkers and therefore develop potential inhibitors in personalized treatment to improve CRC patient survival.

\section{CLINICAL TRIALS OF INTEGRIN-RELATED TARGETS IN GASTROINTESTINAL CANCER}

Several hundred drugs targeting integrins have been identified. The integrin-targeted drugs licensed by some companies may vary from target indications and development stages, for example, some drugs are discontinued in one indication but are tested in others (Raab-Westphal et al., 2017). Here, we conclude the latest stage of clinical trials of integrin-related drugs in gastrointestinal cancer treatment. For example, the combination of the abituzumab (EMD 525797), a monoclonal inhibitory antibody targeting av integrins, with irinotecan and cetuximab were tested in K-ras wild-type metastatic colorectal cancer patients, however, failed their primary endpoints and ended in phase 2 trial (withdrawal study, ClinicalTrials.gov Identifier: NCT03688230). In addition, the humanized monoclonal antibodies etaracizumab and MEDI522, which directed against the human $\alpha v \beta 3$ integrin, were tested in the patients with irinotecan-refractory advanced colorectal cancer and have 
completed its phase 2 trial (ClinicalTrials.gov Identifier: NCT00284817 and NCT00027729).

Although the clinical treatment result is less encouraging, the potential diagnostic value of targeting integrin seems promising. For instance, in monitoring efficacy and adverse events of apatinib in malignancies (e.g. stomach cancer), the 18F-ALFNOTA-PRGD2, which can highly combine with integrin $a v \beta 3$, has completed its phase 4 trial in the monitoring of the antiangiogenic status, and finally propose to evaluate the feasibility of 18F-RGD PET/CT (ClinicalTrials.gov Identifier: NCT03384511). Furthermore, the 18F- $\alpha v \beta 6$-binding-peptide, a radiotracer, for imaging patients with primary tumor or other sites of metastasis (e.g. lung, breast, and colorectal, or pancreatic) is under the early phase 1 trial (ClinicalTrials.gov Identifier: NCT03164486), which may significantly improve the ability to locate the tumor in the patient.

Considering RGD sequence serves as the primary recognition domain in multiple integrins-ECM interactions, such as integrin $\alpha 5 \beta 1, \alpha v \beta 3, \alpha v \beta 5$, and $\alpha v \beta 6$, many researchers have been focused on designing and optimizing the synthetic RGD binding ligands to target certain integrins (Gurrath et al., 1992; Janssen et al., 2002; Meyer et al., 2006; David et al., 2018). Of note, combination of the small molecule antagonist cilengitide, an RGDmimetic cyclicized pentapeptide which target integrin av $\beta 3$ and $\alpha v \beta 5$, with temozolomide and radiation therapy has completed the phase 3 clinical trials in patients with newly diagnosed glioblastoma (ClinicalTrials.gov Identifier: NCT00689221). Nonetheless, the combination of cilengitide with chemotherapy exhibited promising prospects in advanced non-small-cell lung cancer (Vansteenkiste et al., 2015); therefore, application discovery for synthetic integrin ligands in gastrointestinal cancer treatment remains to be investigated.

\section{CONCLUSION AND PERSPECTIVE}

Taken together, aberrant expression of integrins contribute to several metastatic steps including EMT/invasion, intravasation, circulation, extravasation, and colonization in gastrointestinal cancer. In a mechanistic manner, interaction/crosstalk between different ligands (e.g. laminin-5, collagen IV, and fibronectin) or transmembrane receptors (e.g. uPAR, TGF- $\beta$, and EGFR) and integrins mediate the conformational rearrangementdependent activation, which induces a series of downstream pathways to promote gastrointestinal cancer metastasis. Recent findings provide a theoretical basis for the potentiality of integrins as novel diagnostic markers and therapeutic targets for gastrointestinal cancer. Compared to their promising achievements in diagnosis, the therapeutic value of targeting integrins needs further investigation. Specifically, nascent inhibitory peptides, anti-integrins monoclonal antibodies and the combination with other therapeutic approaches (e.g. antibody-drug conjugates, nanoparticle-based delivery, and RNA interference technology) are encouraged to be developed and investigated in clinical trials.
Gastrointestinal cancer exhibits higher propensities to metastasize to the liver, lymph nodes, peritoneal, and then subsequently spread to the lung or other organs (Chen et al., 2012), indicating that a limited number of organs provide a suitable stromal environment for their colonization. It is worth mentioning that there has been an increasing interest in exploring the function of exosomal integrins (including integrin $\alpha 6 \beta 4$, $\alpha 6 \beta 1, \alpha 2 \beta 1, \alpha M \beta 2, \alpha v \beta 3, \alpha v \beta 6$, and $\alpha 5 \beta 1)$ on metastasis, especially the organotropic metastasis, in breast cancer, pancreatic cancer, prostate cancer, and lung cancer metastatic models (Bijnsdorp et al., 2013; Fedele et al., 2015; Hoshino et al., 2015; Singh et al., 2016; Hurwitz and Meckes, 2019; Li X. et al., 2020; Gaballa et al., 2020; Casari et al., 2021; Chen et al., 2021; Wu et al., 2021). However, the essential exosomal integrins involved in gastrointestinal cancer metastasis have not been identified yet. In addition, further studies are needed to focus on the detailed mechanisms involved in exosomal inegrins-mediated premetastatic niche evolution and investigate the potential of exosomal integrin(s) as a marker and driver of cancer metastasis, especially in gastrointestinal cancer metastasis. Clinically, a study titled "Identification of New Diagnostic Protein Markers for Colorectal Cancer (ClinicalTrials.gov Identifier: NCT04394572)", which include focusing on the specific integrins derived from circulating tumor exosomes in the context of colorectal cancer to evaluate the diagnostic performances of related markers, is under the recruiting stage.

Notably, metastatic latency is a clinical phenomenon for many types of cancer, including gastrointestinal cancer, mainly due to cancer cell dormancy. Metastatic dormancy is defined by a relatively long disease-free interval (months, years or even decades, differ from cancer to cancer) between successful therapy or removal of the primary tumor and subsequent clinical relapse with disseminated disease (Anderson et al., 2019). Dormant tumor cells usually exhibit resistance to chemotherapy due to their arrested cell cycle (Naumov et al., 2003) or the protection by the cellular molecules and extracellular components of their microenvironment (Sethi et al., 1999; Weaver et al., 2002; Ghajar et al., 2013). Recently, the factors that maintain tumor cell dormancy in the pre-metastatic niches have been unraveled, including different ECM components, cytokines and other proteins (Anderson et al., 2019), however, about how dormancy is broken remains less understood. Intriguingly, integrins $\beta 1, \alpha 3 \beta 1$, and $\alpha 4 \beta 1$ have been implicated in the reactivation of the dormant breast cancer cells (Shibue and Weinberg, 2009; Chen et al., 2011; Shibue et al., 2012; Shibue et al., 2013; Albrengues et al., 2018), highlighting the importance of integrins-mediated adhesion signaling between metastasisinitiating cells and perivascular niches in metastatic dormancy and reactivation. Therefore, more studies are needed to focus on the role of indicated integrin in gastrointestinal cancer metastatic dormancy and reactivation.

In summary, integrins-mediated gastrointestinal cancer metastasis is a complex and multi-step process. The very concept of designing a metastasis-specific therapeutic should consider which step of the process is best to target, and targeting any stage of the metastatic process requires a 
cancer-specific understanding of the mechanisms involved. We therefore prospectively suggest the following points need to be addressed in further investigations: 1) the dynamics of PTMs, especially glycosylation on integrins during gastrointestinal cancer metastasis; 2) the integrin-associated mechanisms linking immune system/metabolism and metastasis, which is better to understand the integrin dependency; 3) patientderived xenograft and related genetically engineered mouse models will be helpful to explore truly effective agents that block the integrin-specific signaling; and 4) integrins-related RNAi and nanoparticle formulations need to be studied during gastrointestinal cancer metastasis.

\section{REFERENCES}

Ahmed, N., Oliva, K., Wang, Y., Quinn, M., and Rice, G. (2003). Downregulation of Urokinase Plasminogen Activator Receptor Expression Inhibits Erk Signalling with Concomitant Suppression of Invasiveness Due to Loss of uPAR-B1 Integrin Complex in Colon Cancer Cells. Br. J. Cancer 89 (2), 374-384. doi:10.1038/sj.bjc.6601098

Aiello, N. M., and Kang, Y. (2019). Context-dependent EMT Programs in Cancer Metastasis. J. Exp. Med. 216 (5), 1016-1026. doi:10.1084/jem.20181827

Albrengues, J., Shields, M. A., Ng, D., Park, C. G., Ambrico, A., Poindexter, M. E., et al. (2018). Neutrophil Extracellular Traps Produced during Inflammation Awaken Dormant Cancer Cells in Mice. Science 361 (6409), eaao4227. doi:10.1126/science.aao4227

Anderson, J. A., Grabowska, A. M., and Watson, S. A. (2007). PTHrP Increases Transcriptional Activity of the Integrin Subunit a5. Br. J. Cancer 96 (9), 1394-1403. doi:10.1038/sj.bjc.6603720

Anderson, R. L., Balasas, T., Balasas, T., Callaghan, J., Coombes, R. C., Evans, J., et al. (2019). A Framework for the Development of Effective Anti-metastatic Agents. Nat. Rev. Clin. Oncol. 16 (3), 185-204. doi:10.1038/s41571-018-0134-8

Annes, J. P., Chen, Y., Munger, J. S., and Rifkin, D. B. (2004). Integrin $\alpha \mathrm{V} \beta 6-$ mediated Activation of Latent TGF- $\beta$ Requires the Latent TGF- $\beta$ Binding Protein-1. J. Cell Biol. 165 (5), 723-734. doi:10.1083/jcb.200312172

Azevedo, A. S., Follain, G., Patthabhiraman, S., Harlepp, S., and Goetz, J. G. (2015). Metastasis of Circulating Tumor Cells: Favorable Soil or Suitable Biomechanics, or Both? Cell Adhes. Migration 9 (5), 345-356. doi:10.1080/ 19336918.2015.1059563

Bachelder, R. E., Marchetti, A., Falcioni, R., Soddu, S., and Mercurio, A. M. (1999). Activation of P53 Function in Carcinoma Cells by the a6ß34 Integrin. J. Biol. Chem. 274 (29), 20733-20737. doi:10.1074/jbc.274.29.20733

Bandyopadhyay, A., and Raghavan, S. (2009). Defining the Role of Integrin av $\beta 6$ in Cancer. Curr. Drug Targets 10 (7), 645-652. doi:10.2174/ 138945009788680374

Bartolomé, R. A., Barderas, R., Torres, S., Fernandez-Aceñero, M. J., Mendes, M., García-Foncillas, J., et al. (2014a). Cadherin-17 Interacts with $\alpha 2 \beta 1$ Integrin to Regulate Cell Proliferation and Adhesion in Colorectal Cancer Cells Causing Liver Metastasis. Oncogene 33 (13), 1658-1669. doi:10.1038/onc.2013.117

Bartolomé, R. A., Peláez-García, A., Gomez, I., Torres, S., Fernandez-Aceñero, M. J., Escudero-Paniagua, B., et al. (2014b). An RGD Motif Present in Cadherin 17 Induces Integrin Activation and Tumor Growth. J. Biol. Chem. 289 (50), 34801-34814. doi:10.1074/jbc.M114.600502

Bates, R. C., Bellovin, D. I., Brown, C., Maynard, E., Wu, B., Kawakatsu, H., et al. (2005). Transcriptional Activation of Integrin $\beta 6$ During the EpithelialMesenchymal Transition Defines a Novel Prognostic Indicator of Aggressive Colon Carcinoma. J. Clin. Invest. 115 (2), 339-347. doi:10.1172/JCI23183

Beaulieu, J.-F. (2019). Integrin $\alpha 6 \beta 4$ in Colorectal Cancer: Expression, Regulation, Functional Alterations and Use as a Biomarker. Cancers 12 (1), 41. doi:10.3390/ cancers12010041

Benoit, Y. D., Larrivée, J.-F., Groulx, J.-F., Stankova, J., Vachon, P. H., and Beaulieu, J.-F. (2010). Integrin a $8 \beta 1$ Confers Anoikis Susceptibility to Human Intestinal Epithelial Crypt Cells. Biochem. Biophysical Res. Commun. 399 (3), 434-439. doi:10.1016/j.bbrc.2010.07.107

\section{AUTHOR CONTRIBUTIONS}

$\mathrm{SH}$, JW, WL, XH, and QH wrote the manuscript. All the authors contributed to the article and approved the submitted version.

\section{FUNDING}

This work was supported in part by grant from National Natural Science Foundation of China (No. 31800675 to SH) and the Postdoctoral Science Foundation in Jiangsu Province (No. 2018K263C to SH).

Bianchi, A., Gervasi, M. E., and Bakin, A. (2010). Role of $\beta 5$-integrin in EpithelialMesenchymal Transition in Response to TGF- $\beta$. Cell Cycle 9 (8), 1647-1659. doi:10.4161/cc.9.8.11517

Bijnsdorp, I. V., Geldof, A. A., Lavaei, M., Piersma, S. R., van Moorselaar, R. J. A., and Jimenez, C. R. (2013). Exosomal ITGA3 Interferes with Non-cancerous Prostate Cell Functions and Is Increased in Urine Exosomes of Metastatic Prostate Cancer Patients. J. Extracellular Vesicles 2, 22097. doi:10.3402/jev.v2i0.22097

Boudjadi, S., and Beaulieu, J.-F. (2016). MYC and Integrins Interplay in Colorectal Cancer. Oncoscience 3 (2), 50-51. doi:10.18632/oncoscience.293

Boudjadi, S., Bernatchez, G., Sénicourt, B., Beauséjour, M., Vachon, P., Carrier, J., et al. (2017). Involvement of the Integrin $\alpha 1 \beta 1$ in the Progression of Colorectal Cancer. Cancers 9 (8), 96. doi:10.3390/cancers9080096

Boudjadi, S., Carrier, J. C., Groulx, J.-F., and Beaulieu, J.-F. (2016). Integrin $\alpha 1 \beta 1$ Expression Is Controlled by C-MYC in Colorectal Cancer Cells. Oncogene 35 (13), 1671-1678. doi:10.1038/onc.2015.231

Callaway, K. A., Rainey, M. A., Riggs, A. F., Abramczyk, O., and Dalby, K. N. (2006). Properties and Regulation of a Transiently Assembled ERK2.Ets-1 Signaling Complex. Biochemistry 45 (46), 13719-13733. doi:10.1021/bi0610451

Campbell, I. D., and Humphries, M. J. (2011). Integrin Structure, Activation, and Interactions. Cold Spring Harb. Perspect. Biol. 3 (3). doi:10.1101/ cshperspect.a004994

Cantor, D. I., Cheruku, H. R., Nice, E. C., and Baker, M. S. (2015). Integrin $\alpha v \beta 6$ Sets the Stage for Colorectal Cancer Metastasis. Cancer Metastasis Rev. 34 (4), 715-734. doi:10.1007/s10555-015-9591-Z

Cao, Y., Hoeppner, L. H., Bach, S., E, G., Guo, Y., Wang, E., et al. (2013). Neuropilin-2 Promotes Extravasation and Metastasis by Interacting with Endothelial $\alpha 5$ Integrin. Cancer Res. 73 (14), 4579-4590. doi:10.1158/0008-5472.CAN-13-0529

Casari, I., Howard, J. A., Robless, E. E., and Falasca, M. (2021). Exosomal Integrins and Their Influence on Pancreatic Cancer Progression and Metastasis. Cancer Lett. 507, 124-134. doi:10.1016/j.canlet.2021.03.010

Chen, C.-N., Chang, C.-C., Lai, H.-S., Jeng, Y.-M., Chen, C.-I., Chang, K.-J., et al. (2015). Connective Tissue Growth Factor Inhibits Gastric Cancer Peritoneal Metastasis by Blocking Integrin $\alpha 3 \beta 1$-dependent Adhesion. Gastric Cancer 18 (3), 504-515. doi:10.1007/s10120-014-0400-0

Chen, G.-Y., Cheng, J. C.-H., Chen, Y.-F., Yang, J. C.-H., and Hsu, F.-M. (2021). Circulating Exosomal Integrin $\beta 3$ Is Associated with Intracranial Failure and Survival in Lung Cancer Patients Receiving Cranial Irradiation for Brain Metastases: A Prospective Observational Study. Cancers 13 (3), 380. doi: $10.3390 /$ cancers 13030380

Chen, J. L., Gurski, R. R., Takahashi, K., and Andersson, R. (2012). Gastrointestinal Cancer Metastasis. Gastroenterol. Res. Pract. 2012, 415498. doi:10.1155/2012/ 415498

Chen, Q., Zhang, X. H.-F., and Massagué, J. (2011). Macrophage Binding to Receptor VCAM-1 Transmits Survival Signals in Breast Cancer Cells that Invade the Lungs. Cancer Cell 20 (4), 538-549. doi:10.1016/j.ccr.2011.08.025

Chong, Y., Tang, D., Xiong, Q., Jiang, X., Xu, C., Huang, Y., et al. (2016). Galectin-1 from Cancer-Associated Fibroblasts Induces Epithelial-Mesenchymal Transition through $\beta 1$ Integrin-Mediated Upregulation of Glil in Gastric Cancer. J. Exp. Clin. Cancer Res. 35 (1), 175. doi:10.1186/s13046-016-0449-1

Chuang, Y.-C., Wu, H.-Y., Lin, Y.-L., Tzou, S.-C., Chuang, C.-H., Jian, T.-Y., et al. (2018). Blockade of ITGA2 Induces Apoptosis and Inhibits Cell Migration in Gastric Cancer. Biol. Proced. Online 20, 10. doi:10.1186/s12575-018-0073-x 
Cooper, L. A., Shen, T.-L., and Guan, J.-L. (2003). Regulation of Focal Adhesion Kinase by its Amino-Terminal Domain through an Autoinhibitory Interaction. Mol. Cell Biol. 23 (22), 8030-8041. doi:10.1128/MCB.23.22.8030-8041.2003

Dammann, K., Khare, V., and Gasche, C. (2014). Tracing PAKs from GI Inflammation to Cancer. Gut 63 (7), 1173-1184. doi:10.1136/gutjnl-2014306768

David, V., Succar, B. B., de Moraes, J. A., Saldanha-Gama, R. F. G., BarjaFidalgo, C., and Zingali, R. B. (2018). Recombinant and Chimeric Disintegrins in Preclinical Research. Toxins 10 (8), 321. doi:10.3390/ toxins 10080321

Dong, H., Liu, H., Zhou, W., Zhang, F., Li, C., Chen, J., et al. (2019). GLI1 Activation by Non-classical Pathway Integrin av $\beta 3 /$ ERK1/2 Maintains Stem Cell-like Phenotype of Multicellular Aggregates in Gastric Cancer Peritoneal Metastasis. Cell Death Dis. 10 (8), 574. doi:10.1038/s41419-019-1776-x

Elola, M. T., Chiesa, M. E., Alberti, A. F., Mordoh, J., and Fink, N. E. (2005). Galectin-1 Receptors in Different Cell Types. J. Biomed. Sci. 12 (1), 13-29. doi:10.1007/s11373-004-8169-5

Enns, A., Gassmann, P., Schlüter, K., Korb, T., Spiegel, H., Senninger, N., et al. (2004). Integrins Can Directly Mediate Metastatic Tumor Cell Adhesion within the Liver Sinusoids. J. Gastrointest. Surg. 8 (8), 1049-1060. doi:10.1016/ j.gassur.2004.08.016

Enns, A., Korb, T., Schlüter, K., Gassmann, P., Spiegel, H.-U., Senninger, N., et al. (2005). avß5-Integrins Mediate Early Steps of Metastasis Formation. Eur. J. Cancer 41 (7), 1065-1072. doi:10.1016/j.ejca.2004.12.031

Fedele, C., Singh, A., Zerlanko, B. J., Iozzo, R. V., and Languino, L. R. (2015). The avß6 Integrin Is Transferred Intercellularly via Exosomes. J. Biol. Chem. 290 (8), 4545-4551. doi:10.1074/jbc.C114.617662

Feng, W., Huang, W., Chen, J., Qiao, C., Liu, D., Ji, X., et al. (2021). Cxcl12mediated Hoxb5 Overexpression Facilitates Colorectal Cancer Metastasis through Transactivating CXCR4 and ITGB3. Theranostics 11 (6), 2612-2633. doi:10.7150/thno.52199

Ferraro, A., Boni, T., and Pintzas, A. (2014a). EZH2 Regulates Cofilin Activity and Colon Cancer Cell Migration by Targeting ITGA2 Gene. PLoS One 9 (12), e115276. doi:10.1371/journal.pone.0115276

Ferraro, A., Kontos, C. K., Boni, T., Bantounas, I., Siakouli, D., Kosmidou, V., et al. (2014b). Epigenetic Regulation of miR-21 in Colorectal Cancer: ITGB4 as a Novel miR-21 Target and a Three-Gene Network (miR-21-ITGß4-PDCD4) as Predictor of Metastatic Tumor Potential. Epigenetics 9 (1), 129-141. doi:10.4161/epi.26842

Ferraro, A., Mourtzoukou, D., Kosmidou, V., Avlonitis, S., Kontogeorgos, G., Zografos, G., et al. (2013). EZH2 Is Regulated by ERK/AKT and Targets Integrin a2 Gene to Control Epithelial-Mesenchymal Transition and Anoikis in Colon Cancer Cells. Int. J. Biochem. Cell Biol. 45 (2), 243-254. doi:10.1016/j.biocel.2012.10.009

Fransvea, E., Mazzocca, A., Antonaci, S., and Giannelli, G. (2009). Targeting Transforming Growth Factor (TGF)- $\beta$ RI Inhibits Activation of $\beta 1$ Integrin and Blocks Vascular Invasion in Hepatocellular Carcinoma. Hepatology 49 (3), 839-850. doi:10.1002/hep.22731

Fukuda, K., Saikawa, Y., Yagi, H., Wada, N., Takahashi, T., and Kitagawa, Y. (2012). Role of Integrin a 1 Subunits in Gastric Cancer Patients with Peritoneal Dissemination. Mol. Med. Rep. 5 (2), 336-340. doi:10.3892/mmr.2011.642

Gaballa, R., Ali, H. E. A., Mahmoud, M. O., Rhim, J. S., Ali, H. I., Salem, H. F., et al. (2020). Exosomes-Mediated Transfer of Itga2 Promotes Migration and Invasion of Prostate Cancer Cells by Inducing Epithelial-Mesenchymal Transition. Cancers 12 (8), 2300. doi:10.3390/cancers 12082300

Gahmberg, C. G., Grönholm, M., Madhavan, S., Jahan, F., Mikkola, E., Viazmina, L., et al. (2019). Regulation of Cell Adhesion: a Collaborative Effort of Integrins, Their Ligands, Cytoplasmic Actors, and Phosphorylation. Quart. Rev. Biophys. 52, e10. doi:10.1017/s0033583519000088

Gan, L., Meng, J., Xu, M., Liu, M., Qi, Y., Tan, C., et al. (2018). Extracellular Matrix Protein 1 Promotes Cell Metastasis and Glucose Metabolism by Inducing Integrin $\beta 4 /$ FAK/SOX2/HIF-1 $\alpha$ Signaling Pathway in Gastric Cancer. Oncogene 37 (6), 744-755. doi:10.1038/onc.2017.363

Ganguly, K. K., Pal, S., Moulik, S., and Chatterjee, A. (2013). Integrins and Metastasis. Cell Adh. Migr. 7 (3), 251-261. doi:10.4161/cam.23840

Gao, H., Peng, C., Liang, B., Shahbaz, M., Liu, S., Wang, B., et al. (2014). $\beta 6$ Integrin Induces the Expression of Metalloproteinase- 3 and Metalloproteinase- 9 in
Colon Cancer Cells via ERK-ETS1 Pathway. Cancer Lett. 354 (2), 427-437. doi:10.1016/j.canlet.2014.08.017

Ghajar, C. M., Peinado, H., Mori, H., Matei, I. R., Evason, K. J., Brazier, H., et al. (2013). The Perivascular Niche Regulates Breast Tumour Dormancy. Nat. Cell Biol. 15 (7), 807-817. doi:10.1038/ncb2767

Giancotti, F. G., and Ruoslahti, E. (1999). Integrin Signaling. Science 285 (5430), 1028-1033. doi:10.1126/science.285.5430.1028

Goldfinger, L. E., Han, J., Kiosses, W. B., Howe, A. K., and Ginsberg, M. H. (2003) Spatial Restriction of a4 Integrin Phosphorylation Regulates Lamellipodial Stability and $\alpha 4 \beta 1$-dependent Cell Migration. J. Cell Biol. 162 (4), 731-741. doi:10.1083/jcb.200304031

Groulx, J. F., Boudjadi, S., and Beaulieu, J. F. (2018). MYC Regulates a6 Integrin Subunit Expression and Splicing Under Its Pro-Proliferative ITGA6A Form in Colorectal Cancer Cells. Cancers (Basel) 10 (2). doi:10.3390/cancers10020042

Guan, X. (2015). Cancer Metastases: Challenges and Opportunities. Acta Pharm. Sin. B 5 (5), 402-418. doi:10.1016/j.apsb.2015.07.005

Guha, D., Saha, T., Bose, S., Chakraborty, S., Dhar, S., Khan, P., et al. (2019). Integrin-EGFR Interaction Regulates Anoikis Resistance in Colon Cancer Cells. Apoptosis 24 (11-12), 958-971. doi:10.1007/s10495-019-01573-5

Gurrath, M., Müller, G., Kessler, H., Aumailley, M., and Timpl, R. (1992). Conformation/activity Studies of Rationally Designed Potent Anti-adhesive RGD Peptides. Eur. J. Biochem. 210 (3), 911-921. doi:10.1111/j.14321033.1992.tb17495.x

Hakanpaa, L., Sipila, T., Leppanen, V.-M., Gautam, P., Nurmi, H., Jacquemet, G., et al. (2015). Endothelial Destabilization by Angiopoietin-2 via Integrin $\beta 1$ Activation. Nat. Commun. 6, 5962. doi:10.1038/ncomms6962

Hamidi, H., and Ivaska, J. (2018). Every Step of the Way: Integrins in Cancer Progression and Metastasis. Nat. Rev. Cancer 18 (9), 533-548. doi:10.1038/ s41568-018-0038-Z

Hang, Q., Isaji, T., Hou, S., Wang, Y., Fukuda, T., and Gu, J. (2017). A Key Regulator of Cell Adhesion: Identification and Characterization of Important N -Glycosylation Sites on Integrin a5 for Cell Migration. Mol. Cell. Biol 37 (9). doi:10.1128/mcb.00558-16

Hashida, H., Takabayashi, A., Tokuhara, T., Taki, T., Kondo, K., Kohno, N., et al. (2002). Integrin a3 Expression as a Prognostic Factor in Colon Cancer: Association with MRP-1/CD9 and KAI1/CD82. Int. J. Cancer 97 (4), 518-525. doi:10.1002/ijc. 1625

Hedrick, E., Lee, S.-o., and Safe, S. (2017). The Nuclear Orphan Receptor NR4A1 Regulates $\beta 1$-integrin Expression in Pancreatic and colon Cancer Cells and Can Be Targeted by NR4A1 Antagonists. Mol. Carcinog. 56 (9), 2066-2075. doi:10.1002/mc.22662

Hirano, T., Shinsato, Y., Tanabe, K., Higa, N., Kamil, M., Kawahara, K., et al. (2020). FARP1 Boosts CDC42 Activity from Integrin $\alpha v \beta 5$ Signaling and Correlates with Poor Prognosis of Advanced Gastric Cancer. Oncogenesis 9 (2), 13. doi:10.1038/s41389-020-0190-7

Hong, D., Zhang, X., Li, R., Yu, J., Lou, Y., He, Q., et al. (2019). Deletion of TMEM268 Inhibits Growth of Gastric Cancer Cells by Downregulating the ITGB4 Signaling Pathway. Cell Death Differ. 26 (8), 1453-1466. doi:10.1038/ s41418-018-0223-3

Horton, E. R., Humphries, J. D., James, J., Jones, M. C., Askari, J. A., and Humphries, M. J. (2016). The Integrin Adhesome Network at a Glance. J. Cell Sci. 129 (22), 4159-4163. doi:10.1242/jcs.192054

Hoshino, A., Costa-Silva, B., Shen, T.-L., Rodrigues, G., Hashimoto, A., Tesic Mark, M., et al. (2015). Tumour Exosome Integrins Determine Organotropic Metastasis. Nature 527 (7578), 329-335. doi:10.1038/nature15756

Hou, S., Hang, Q., Isaji, T., Lu, J., Fukuda, T., and Gu1, J. (2016). Importance of Membrane-proximal N-glycosylation on Integrin $\beta 1$ in its Activation and Complex Formation. FASEB J. 30 (12), 4120-4131. doi:10.1096/fj.201600665R

Hu, C., Ni, Z., Li, B.-s., Yong, X., Yang, X., Zhang, J.-w., et al. (2017). hTERT Promotes the Invasion of Gastric Cancer Cells by Enhancing FOXO3a Ubiquitination and Subsequent ITGB1 Upregulation. Gut 66 (1), 31-42. doi:10.1136/gutjnl-2015-309322

Hurwitz, S. N., and Meckes, D. G., Jr. (2019). Extracellular Vesicle Integrins Distinguish Unique Cancers. Proteomes 7 (2), 14. doi:10.3390/ proteomes7020014

Huttenlocher, A., and Horwitz, A. R. (2011). Integrins in Cell Migration. Cold Spring Harb. Perspect. Biol. 3 (9), a005074. doi:10.1101/cshperspect.a005074 
Hynes, R. O. (2002). Integrins: Bidirectional, Allosteric Signaling Machines. Cell 110 (6), 673-687. doi:10.1016/s0092-8674(02)00971-6

Imanishi, Y., Hu, B., Jarzynka, M. J., Guo, P., Elishaev, E., Bar-Joseph, I., et al. (2007). Angiopoietin-2 Stimulates Breast Cancer Metastasis through the $\alpha 5 \beta 1$ Integrin-Mediated Pathway. Cancer Res. 67 (9), 4254-4263. doi:10.1158/00085472.CAN-06-4100

Isaac, J., Tarapore, P., Zhang, X., Lam, Y.-W., and Ho, S.-M. (2012). Site-Specific S-Nitrosylation of Integrin a6 Increases the Extent of Prostate Cancer Cell Migration by Enhancing Integrin $\beta 1$ Association and Weakening Adherence to Laminin-1. Biochemistry 51 (48), 9689-9697. doi:10.1021/bi3012324

Janouskova, H., Ray, A.-M., Noulet, F., Lelong-Rebel, I., Choulier, L., Schaffner, F., et al. (2013). Activation of P53 Pathway by Nutlin-3a Inhibits the Expression of the Therapeutic Target a5 Integrin in Colon Cancer Cells. Cancer Lett. 336 (2), 307-318. doi:10.1016/j.canlet.2013.03.018

Janssen, M. L., Oyen, W. J., Dijkgraaf, I., Massuger, L. F., Frielink, C., Edwards, D. S., et al. (2002). Tumor Targeting with Radiolabeled Alpha(v)beta(3) Integrin Binding Peptides in a Nude Mouse Model. Cancer Res. 62 (21), 6146-6151.

Jin, H., Ying, X., Que, B., Wang, X., Chao, Y., Zhang, H., et al. (2019). N6methyladenosine Modification of ITGA6 mRNA Promotes the Development and Progression of Bladder Cancer. EBioMedicine 47, 195-207. doi:10.1016/ j.ebiom.2019.07.068

Kariya, Y., Kariya, Y., and Gu, J. (2017). Roles of Integrin a6 84 Glycosylation in Cancer. Cancers (Basel) 9 (7). doi:10.3390/cancers9070079

Kariya, Y., Oyama, M., Suzuki, T., and Kariya, Y. (2021). av $\beta 3$ Integrin Induces Partial EMT Independent of TGF- $\beta$ Signaling. Commun. Biol. 4 (1), 490. doi:10.1038/s42003-021-02003-6

Katabami, K., Kato, T., Sano, R., Ogura, M., Mizuno, H., Itoh, S., et al. (2006). Characterization of the Promoter for the a 3 Integrin Gene in Various Tumor Cell Lines: Roles of the Ets- and Sp-Family of Transcription Factors. J. Cell Biochem. 97 (3), 530-543. doi:10.1002/jcb.20663

Kim, S.-H., Turnbull, J., and Guimond, S. (2011). Extracellular Matrix and Cell Signalling: the Dynamic Cooperation of Integrin, Proteoglycan and Growth Factor Receptor. J. Endocrinol. 209 (2), 139-151. doi:10.1530/JOE-10-0377

Kim, S., Kang, H. Y., Nam, E. H., Choi, M. S., Zhao, X. F., Hong, C. S., et al. (2010). TMPRSS4 Induces Invasion and Epithelial-Mesenchymal Transition through Upregulation of Integrin $\alpha 5$ and its Signaling Pathways. Carcinogenesis 31 (4), 597-606. doi:10.1093/carcin/bgq024

Kline, C. L. B., Olson, T. L., and Irby, R. B. (2009). Src Activity Alters $\alpha 3$ Integrin Expression in Colon Tumor Cells. Clin. Exp. Metastasis 26 (2), 77-87. doi:10.1007/s10585-008-9215-x

Knowles, L. M., Gurski, L. A., Engel, C., Gnarra, J. R., Maranchie, J. K., and Pilch, J. (2013). Integrin $\alpha v \beta 3$ and Fibronectin Upregulate Slug in Cancer Cells to Promote Clot Invasion and Metastasis. Cancer Res. 73 (20), 6175-6184. doi:10.1158/0008-5472.CAN-13-0602

Kokkinos, M. I., Brown, H. J., and de Iongh, R. U. (2007). Focal Adhesion Kinase (FAK) Expression and Activation during Lens Development. Mol. Vis. 13, 418-430.

Koster, J., Geerts, D., Favre, B., Borradori, L., and Sonnenberg, A. (2003). Analysis of the Interactions between BP180, BP230, Plectin and the Integrin $\alpha 6 \beta 4$ Important for Hemidesmosome Assembly. J. Cell Sci. 116 (Pt 2), 387-399. doi: $10.1242 /$ jcs. 00241

Kuo, Y.-C., He, X., Coleman, A. J., Chen, Y.-J., Dasari, P., Liou, J., et al. (2018). Structural Analyses of FERM Domain-Mediated Membrane Localization of FARP1. Sci. Rep. 8 (1), 10477. doi:10.1038/s41598-018-28692-4

Lambert, A. W., Pattabiraman, D. R., and Weinberg, R. A. (2017). Emerging Biological Principles of Metastasis. Cell 168 (4), 670-691. doi:10.1016/ j.cell.2016.11.037

Lee, M.-S., Kim, T. Y., Kim, Y.-B., Lee, S.-Y., Ko, S.-G., Jong, H.-S., et al. (2005). The Signaling Network of Transforming Growth Factor $\beta 1$, Protein Kinase C 8 , and Integrin Underlies the Spreading and Invasiveness of Gastric Carcinoma Cells. Mol. Cell Biol. 25 (16), 6921-6936. doi:10.1128/MCB.25.16.6921-6936.2005

Li, E., Wei, B., Wang, X., and Kang, R. (2020). METTL3 Enhances Cell Adhesion through Stabilizing Integrin $\beta 1 \mathrm{mRNA}$ via an m6A-HuR-dependent Mechanism in Prostatic Carcinoma. Am. J. Cancer Res. 10 (3), 1012-1025.

Li, J., Jiang, Y., Chen, C., Tan, W., Li, P., Chen, G., et al. (2020). Integrin $\beta 4$ Is an Effective and Efficient Marker in Synchronously Highlighting Lymphatic and Blood Vascular Invasion, and Perineural Aggression in Malignancy. Am. J. Surg. Pathol. 44 (5), 681-690. doi:10.1097/PAS.0000000000001451
Li, M., Jiang, X., Wang, G., Zhai, C., Liu, Y., Li, H., et al. (2019). ITGB4 is a Novel Prognostic Factor in Colon Cancer. J. Cancer 10 (21), 5223-5233. doi:10.7150/ jca.29269

Li, X.-L., Liu, L., Li, D.-D., He, Y.-P., Guo, L.-H., Sun, L.-P., et al. (2017). Integrin $\beta 4$ Promotes Cell Invasion and Epithelial-Mesenchymal Transition through the Modulation of Slug Expression in Hepatocellular Carcinoma. Sci. Rep. 7, 40464. doi:10.1038/srep40464

Li, X., Tang, M., Zhu, Q., Wang, X., Lin, Y., and Wang, X. (2020). The Exosomal Integrin $a 5 \beta 1 / \mathrm{AEP}$ Complex Derived from Epithelial Ovarian Cancer Cells Promotes Peritoneal Metastasis through Regulating Mesothelial Cell Proliferation and Migration. Cell Oncol. 43 (2), 263-277. doi:10.1007/ s13402-019-00486-4

Li, X., Wang, J., Zhang, C., Lin, C., Zhang, J., Zhang, W., et al. (2018). Circular RNA circITGA7 Inhibits Colorectal Cancer Growth and Metastasis by Modulating the Ras Pathway and Upregulating Transcription of its Host geneITGA7. J. Pathol. 246 (2), 166-179. doi:10.1002/path.5125

Li, Z., Zhang, L., Zhao, Y., Li, H., Xiao, H., Fu, R., et al. (2013). Cell-surface GRP78 Facilitates Colorectal Cancer Cell Migration and Invasion. Int. J. Biochem. Cell Biol. 45 (5), 987-994. doi:10.1016/j.biocel.2013.02.002

Lin, B.-R., Chang, C.-C., Chen, L.-R., Wu, M.-H., Wang, M.-Y., Kuo, I.-H., et al. (2007). Cysteine-rich 61 (CCN1) Enhances Chemotactic Migration, Transendothelial Cell Migration, and Intravasation by Concomitantly UpRegulating Chemokine Receptor 1 and 2. Mol. Cancer Res. 5 (11), 1111-1123. doi:10.1158/1541-7786.MCR-06-0289

Lin, M.-T., Chang, C.-C., Lin, B.-R., Yang, H.-Y., Chu, C.-Y., Wu, M.-H., et al. (2007). Elevated Expression of Cyr61 Enhances Peritoneal Dissemination of Gastric Cancer Cells through Integrin $\alpha 2 \beta 1$. J. Biol. Chem. 282 (47), 34594-34604. doi:10.1074/jbc.M706600200

Liu, J., Zhang, Z., Li, X., Chen, J., Wang, G., Tian, Z., et al. (2018). Forkhead Box C1 Promotes Colorectal Cancer Metastasis through Transactivating ITGA7 and FGFR4 Expression. Oncogene 37 (41), 5477-5491. doi:10.1038/s41388-0180355-4

Lobert, V. H., Brech, A., Pedersen, N. M., Wesche, J., Oppelt, A., Malerød, L., et al. (2010). Ubiquitination of $\alpha 5 \beta 1$ Integrin Controls Fibroblast Migration through Lysosomal Degradation of Fibronectin-Integrin Complexes. Develop. Cell 19 (1), 148-159. doi:10.1016/j.devcel.2010.06.010

Ludbrook, S. B., Barry, S. T., Delves, C. J., and Horgan, C. M. T. (2003). The Integrin $\alpha v \beta 3$ Is a Receptor for the Latency-Associated Peptides of Transforming Growth Factors $\beta 1$ and $\beta 3$. Biochem. J. 369 (Pt 2), 311-318. doi:10.1042/BJ20020809

Lv, X.-H., Liu, B.-Q., Li, X.-M., Wang, X.-C., Li, X.-L., Ahmed, N., et al. (2016). Integrin a4 Induces Lymphangiogenesis and Metastasis via Upregulation of VEGF-C in Human Colon Cancer. Anat. Rec. 299 (6), 741-747. doi:10.1002/ar.23338

Ma, C., Rong, Y., Radiloff, D. R., Datto, M. B., Centeno, B., Bao, S., et al. (2008). Extracellular Matrix Protein Ig-H3/TGFBI Promotes Metastasis of colon Cancer by Enhancing Cell Extravasation. Genes Develop. 22 (3), 308-321. doi:10.1101/gad.1632008

Mamuya, F. A., and Duncan, M. K. (2012). aV Integrins and TGF- $\beta$-Induced EMT: a circle of Regulation. J. Cell Mol. Med. 16 (3), 445-455. doi:10.1111/j.15824934.2011.01419.x

Marchiò, S., Soster, M., Cardaci, S., Muratore, A., Bartolini, A., Barone, V., et al. (2012). A Complex of a 6 Integrin and E-cadherin Drives Liver Metastasis of Colorectal Cancer Cells through Hepatic Angiopoietin-like 6. EMBO Mol. Med. 4 (11), 1156-1175. doi:10.1002/emmm.201101164

Margadant, C., and Sonnenberg, A. (2010). Integrin-TGF- $\beta$ Crosstalk in Fibrosis, Cancer and Wound Healing. EMBO Rep. 11 (2), 97-105. doi:10.1038/ embor.2009.276

Marsico, G., Russo, L., Quondamatteo, F., and Pandit, A. (2018). Glycosylation and Integrin Regulation in Cancer. Trends Cancer 4 (8), 537-552. doi:10.1016/ j.trecan.2018.05.009

Matsuoka, T., Yashiro, M., Nishioka, N., Hirakawa, K., Olden, K., and Roberts, J. D. (2012). PI3K/Akt Signalling is Required for the Attachment and Spreading, and Growth In Vivo of Metastatic Scirrhous Gastric Carcinoma. Br. J. Cancer 106 (9), 1535-1542. doi:10.1038/bjc.2012.107

McCarty, J. H. (2008), av Integrins Lead the Way for Colorectal Metastases. Clin. Cancer Res. 14 (20), 6351-6353. doi:10.1158/1078-0432.CCR-08-1847

Meves, A., Geiger, T., Zanivan, S., DiGiovanni, J., Mann, M., and Fässler, R. (2011). $\beta 1$ Integrin Cytoplasmic Tyrosines Promote Skin Tumorigenesis Independent 
of Their Phosphorylation. Proc. Natl. Acad. Sci. 108 (37), 15213-15218. doi:10.1073/pnas.1105689108

Meyer, A., Auernheimer, J., Modlinger, A., and Kessler, H. (2006). Targeting RGD Recognizing Integrins: Drug Development, Biomaterial Research, Tumor Imaging and Targeting. Curr. Pharm. Des. 12 (22), 2723-2747. doi:10.2174/ 138161206777947740

Min, J., Han, T.-S., Sohn, Y., Shimizu, T., Choi, B., Bae, S.-W., et al. (2020). microRNA-30a Arbitrates Intestinal-type Early Gastric Carcinogenesis by Directly Targeting ITGA2. Gastric Cancer 23 (4), 600-613. doi:10.1007/ s10120-020-01052-w

Monnier, Y., Farmer, P., Bieler, G., Imaizumi, N., Sengstag, T., Alghisi, G. C., et al. (2008). CYR61 and $\alpha V \beta 5$ Integrin Cooperate to Promote Invasion and Metastasis of Tumors Growing in Preirradiated Stroma. Cancer Res. 68 (18), 7323-7331. doi:10.1158/0008-5472.can-08-0841

Mori, S., Kodaira, M., Ito, A., Okazaki, M., Kawaguchi, N., Hamada, Y., et al. (2015). Enhanced Expression of Integrin $\alpha v \beta 3$ Induced by TGF- $\beta$ Is Required for the Enhancing Effect of Fibroblast Growth Factor 1 (FGF1) in TGF$\beta$-Induced Epithelial-Mesenchymal Transition (EMT) in Mammary Epithelial Cells. PLoS One 10 (9), e0137486. doi:10.1371/journal.pone.0137486

Murphy, J. M., Jeong, K., and Lim, S.-T. S. (2020). FAK Family Kinases in Vascular Diseases. Int. J. Mol. Sci. 21 (10), 3630. doi:10.3390/ijms21103630

Nam, E.-H., Lee, Y., Moon, B., Lee, J. W., and Kim, S. (2015). Twist1 and AP-1 Cooperatively Upregulate Integrin a5 Expression to Induce Invasion and the Epithelial-Mesenchymal Transition. Carcinogenesis 36 (3), 327-337. doi:10.1093/carcin/bgv005

Nam, E.-H., Lee, Y., Zhao, X.-F., Park, Y.-K., Lee, J. W., and Kim, S. (2014). ZEB2Sp1 Cooperation Induces Invasion by Upregulating Cadherin-11 and Integrin a5 Expression. Carcinogenesis 35 (2), 302-314. doi:10.1093/carcin/bgt340

Naumov, G. N., Townson, J. L., MacDonald, I. C., Wilson, S. M., Bramwell, V. H. C., Groom, A. C., et al. (2003). Ineffectiveness of Doxorubicin Treatment on Solitary Dormant Mammary Carcinoma Cells or Late-Developing Metastases. Breast Cancer Res. Treat. 82 (3), 199-206. doi:10.1023/B: BREA.0000004377.12288.3c

Ni, H., Dydensborg, A. B., Herring, F. E., Basora, N., Gagné, D., Vachon, P. H., et al. (2005). Upregulation of a Functional Form of the $\beta 4$ Integrin Subunit in Colorectal Cancers Correlates with C-Myc Expression. Oncogene 24 (45), 6820-6829. doi:10.1038/sj.onc.1208848

Ou, J., Peng, Y., Deng, J., Miao, H., Zhou, J., Zha, L., et al. (2014). Endothelial CellDerived Fibronectin Extra Domain A Promotes Colorectal Cancer Metastasis via Inducing Epithelial-Mesenchymal Transition. Carcinogenesis 35 (7), 1661-1670. doi:10.1093/carcin/bgu090

Oxley, C. L., Anthis, N. J., Lowe, E. D., Vakonakis, I., Campbell, I. D., and Wegener, L. (2008). An Integrin Phosphorylation Switch. J. Biol. Chem. 283 (9), 5420-5426. doi:10.1074/jbc.M709435200

Paoli, P., Giannoni, E., and Chiarugi, P. (2013). Anoikis Molecular Pathways and its Role in Cancer Progression. Biochim. Biophys. Acta (Bba) - Mol. Cell Res. 1833 (12), 3481-3498. doi:10.1016/j.bbamcr.2013.06.026

Park, J., Song, S.-H., Kim, T. Y., Choi, M.-C., Jong, H.-S., Kim, T.-Y., et al. (2004). Aberrant Methylation of Integrin a4 Gene in Human Gastric Cancer Cells. Oncogene 23 (19), 3474-3480. doi:10.1038/sj.onc.1207470

Peng, C., Zou, X., Xia, W., Gao, H., Li, Z., Liu, N., et al. (2018). Integrin av $\beta 6$ Plays a Bi-directional Regulation Role between Colon Cancer Cells and CancerAssociated Fibroblasts. Biosci. Rep. 38 (6). doi:10.1042/BSR20180243

Peng, Z., Wang, C. X., Fang, E. H., Wang, G. B., and Tong, Q. (2014). Role of Epithelial-Mesenchymal Transition in Gastric Cancer Initiation and Progression. World J. Gastroenterol. 20 (18), 5403-5410. doi:10.3748/ wjg.v20.i18.5403

Pinho, S. S., Figueiredo, J., Cabral, J., Carvalho, S., Dourado, J., Magalhães, A., et al. (2013). E-cadherin and Adherens-Junctions Stability in Gastric Carcinoma: Functional Implications of Glycosyltransferases Involving N-Glycan Branching Biosynthesis, N-Acetylglucosaminyltransferases III and V. Biochim. Biophys. Acta (Bba) - Gen. Subjects 1830 (3), 2690-2700. doi:10.1016/ j.bbagen.2012.10.021

Pouliot, N., Connolly, L. M., Moritz, R. L., Simpson, R. J., and Burgess, A. W. (2000). Colon Cancer Cells Adhesion and Spreading on Autocrine Laminin-10 Is Mediated by Multiple Integrin Receptors and Modulated by EGF Receptor Stimulation. Exp. Cell Res. 261 (2), 360-371. doi:10.1006/excr.2000.5065
Raab-Westphal, S., Marshall, J., and Goodman, S. (2017). Integrins as Therapeutic Targets: Successes and Cancers. Cancers 9 (9), 110. doi: $10.3390 /$ cancers 9090110

Rau, B., Brandl, A., Brandl, A., Piso, P., Pelz, J., Busch, P., et al. (2020). Peritoneal Metastasis in Gastric Cancer: Results from the German Database. Gastric Cancer 23 (1), 11-22. doi:10.1007/s10120-019-00978-0

Ren, J., Xu, S., Guo, D., Zhang, J., and Liu, S. (2014). Increased Expression of a5 $\beta 1$ integrin Is a Prognostic Marker for Patients with Gastric Cancer. Clin. Transl. Oncol. 16 (7), 668-674. doi:10.1007/s12094-013-1133-y

Reyes-Reyes, M. E., George, M. D., Roberts, J. D., and Akiyama, S. K. (2006). P-selectin Activates Integrin-Mediated Colon Carcinoma Cell Adhesion to Fibronectin. Exp. Cell Res. 312 (20), 4056-4069. doi:10.1016/j.yexcr.2006.09.008

Robertson, J. H., Yang, S. Y., Winslet, M. C., and Seifalian, A. M. (2009). Functional Blocking of Specific Integrins Inhibit Colonic Cancer Migration. Clin. Exp. Metastasis 26 (7), 769-780. doi:10.1007/s10585-009-9276-5

Rohwer, N., Welzel, M., Daskalow, K., Pfander, D., Wiedenmann, B., Detjen, K., et al. (2008). Hypoxia-Inducible Factor 1a Mediates Anoikis Resistance via Suppression of a5 Integrin. Cancer Res. 68 (24), 10113-10120. doi:10.1158/ 0008-5472.CAN-08-1839

Saito, Y., Sekine, W., Sano, R., Komatsu, S., Mizuno, H., Katabami, K., et al. (2010). Potentiation of Cell Invasion and Matrix Metalloproteinase Production by a3 31 Integrin-Mediated Adhesion of Gastric Carcinoma Cells to Laminin-5. Clin. Exp. Metastasis 27 (4), 197-205. doi:10.1007/s10585-010-9314-3

Schramm, K., Krause, K., Bittroff-Leben, A., Goldin-Lang, P., Thiel, E., and Kreuser, E.-D. (2000). Activated K-Ras Is Involved in Regulation of Integrin Expression in Human Colon Carcinoma Cells. Int. J. Cancer 87 (2), 155-164. doi:10.1002/1097-0215(20000715)87:2<155:aid-ijc1>3.0.co;2-j

Sethi, T., Rintoul, R. C., Moore, S. M., MacKinnon, A. C., Salter, D., Choo, C., et al. (1999). Extracellular Matrix Proteins Protect Small Cell Lung Cancer Cells against Apoptosis: a Mechanism for Small Cell Lung Cancer Growth and Drug Resistance In Vivo. Nat. Med. 5 (6), 662-668. doi:10.1038/9511

Shi, W., He, J., Huang, Y., Zeng, Z., Feng, Z., Xu, H., et al. (2021). Integrin $\beta 5$ Enhances the Malignancy of Human Colorectal Cancer by Increasing the TGF$\beta$ Signaling. Anticancer Drugs 32 (7), 717-726. doi:10.1097/ CAD.0000000000001050

Shibue, T., Brooks, M. W., Inan, M. F., Reinhardt, F., and Weinberg, R. A. (2012). The Outgrowth of Micrometastases Is Enabled by the Formation of Filopodium-like Protrusions. Cancer Discov. 2 (8), 706-721. doi:10.1158/ 2159-8290.CD-11-0239

Shibue, T., Brooks, M. W., and Weinberg, R. A. (2013). An Integrin-Linked Machinery of Cytoskeletal Regulation that Enables Experimental Tumor Initiation and Metastatic Colonization. Cancer Cell 24 (4), 481-498. doi:10.1016/j.ccr.2013.08.012

Shibue, T., and Weinberg, R. A. (2009). Integrin $\beta 1$-focal Adhesion Kinase Signaling Directs the Proliferation of Metastatic Cancer Cells Disseminated in the Lungs. Proc. Natl. Acad. Sci. 106 (25), 10290-10295. doi:10.1073/ pnas. 0904227106

Singh, A., Fedele, C., Lu, H., Nevalainen, M. T., Keen, J. H., and Languino, L. R. (2016). Exosome-mediated Transfer of av $\beta 3$ Integrin from Tumorigenic to Nontumorigenic Cells Promotes a Migratory Phenotype. Mol. Cancer Res. 14 (11), 1136-1146. doi:10.1158/1541-7786.MCR-16-0058

Slik, K., Blom, S., Turkki, R., Välimäki, K., Kurki, S., Mustonen, H., et al. (2019). Combined Epithelial Marker Analysis of Tumour Budding in Stage II Colorectal Cancer. J. Pathol. Clin. Res. 5 (1), 63-78. doi:10.1002/cjp2.119

Smith, H. W., and Marshall, C. J. (2010). Regulation of Cell Signalling by uPAR. Nat. Rev. Mol. Cell Biol. 11 (1), 23-36. doi:10.1038/nrm2821

Sowmya, G., Khan, J. M., Anand, S., Ahn, S. B., Baker, M. S., and Ranganathan, S. (2014). A Site for Direct Integrin av $\beta 6 \cdot u P A R$ Interaction from Structural Modelling and Docking. J. Struct. Biol. 185 (3), 327-335. doi:10.1016/ j.jsb.2014.01.001

Springer, T. A., and Dustin, M. L. (2012). Integrin Inside-Out Signaling and the Immunological Synapse. Curr. Opin. Cell Biol. 24 (1), 107-115. doi:10.1016/ j.ceb.2011.10.004

Sun, Q., Shang, Y., Sun, F., Dong, X., Niu, J., and Li, F. (2020). Interleukin-6 Promotes Epithelial-Mesenchymal Transition and Cell Invasion through Integrin $\beta 6$ Upregulation in Colorectal Cancer. Oxidative Med. Cell Longevity 2020, 1-13. doi:10.1155/2020/8032187 
Sun, Q., Sun, F., Wang, B., Liu, S., Niu, W., Liu, E., et al. (2014). Interleukin-8 Promotes Cell Migration through Integrin av $\beta 6$ Upregulation in Colorectal Cancer. Cancer Lett. 354 (2), 245-253. doi:10.1016/j.canlet.2014.08.021

Sung, H., Ferlay, J., Siegel, R. L., Laversanne, M., Soerjomataram, I., Jemal, A., et al. (2021). Global Cancer Statistics 2020: GLOBOCAN Estimates of Incidence and Mortality Worldwide for 36 Cancers in 185 Countries. CA Cancer J. Clin. 71 (3), 209-249. doi:10.3322/caac.21660

Tapial Martínez, P., López Navajas, P., and Lietha, D. (2020). FAK Structure and Regulation by Membrane Interactions and Force in Focal Adhesions. Biomolecules 10 (2), 179. doi:10.3390/biom10020179

Thongchot, S., Singsuksawat, E., Sumransub, N., Pongpaibul, A., Trakarnsanga, A., Thuwajit, P., et al. (2020). Periostin Regulates Autophagy through Integrin a5 31 or a6 34 and an AKT-dependent Pathway in Colorectal Cancer Cell Migration. J. Cel. Mol. Med. 24 (21), 12421-12432. doi:10.1111/jcmm.15756

Tian, L., Chen, M., He, Q., Yan, Q., and Zhai, C. (2020). MicroRNA199a5p Suppresses Cell Proliferation, Migration and Invasion by Targeting ITGA3 in Colorectal Cancer. Mol. Med. Rep. 22 (3), 2307-2317. doi:10.3892/ mmr.2020.11323

Vansteenkiste, J., Barlesi, F., Waller, C. F., Bennouna, J., Gridelli, C., Goekkurt, E., et al. (2015). Cilengitide Combined with Cetuximab and Platinum-Based Chemotherapy as First-Line Treatment in Advanced Non-small-cell Lung Cancer (NSCLC) Patients: Results of an Open-Label, Randomized, Controlled Phase II Study (CERTO). Ann. Oncol. 26 (8), 1734-1740. doi:10.1093/annonc/mdv219

Vega, M. E., Kastberger, B., Wehrle-Haller, B., and Schwarzbauer, J. E. (2020). Stimulation of Fibronectin Matrix Assembly by Lysine Acetylation. Cells 9 (3), 655. doi: $10.3390 /$ cells 9030655

Vu, T., and Datta, P. (2017). Regulation of EMT in Colorectal Cancer: A Culprit in Metastasis. Cancers 9 (12), 171. doi:10.3390/cancers9120171

Waisberg, J., De Souza Viana, L., Affonso Junior, R. J., Silva, S. R., Denadai, M. V., Margeotto, F. B., et al. (2014). Overexpression of the ITGAV Gene Is Associated with Progression and Spread of Colorectal Cancer. Anticancer Res. 34 (10), 5599-5607.

Walker, C., Mojares, E., and Del Rio Hernandez, A. (2018). Role of Extracellular Matrix in Development and Cancer Progression. Int. J. Mol. Sci. 19 (10). doi:10.3390/ijms19103028

Wang, H., Chen, H., Jiang, Z., Lin, Y., Wang, X., Xiang, J., et al. (2019). Integrin Subunit aV Promotes Growth, Migration, and Invasion of Gastric Cancer Cells. Pathol. - Res. Pract. 215 (9), 152531. doi:10.1016/j.prp.2019.152531

Wang, X., Che, X., Yu, Y., Cheng, Y., Bai, M., Yang, Z., et al. (2020). Hypoxiaautophagy axis Induces VEGFA by Peritoneal Mesothelial Cells to Promote Gastric Cancer Peritoneal Metastasis through an Integrin a5-fibronectin Pathway. J. Exp. Clin. Cancer Res. 39 (1), 221. doi:10.1186/s13046-02001703-X

Weaver, V. M., Lelièvre, S., Lakins, J. N., Chrenek, M. A., Jones, J. C. R., Giancotti, F., et al. (2002). $\beta 4$ Integrin-dependent Formation of Polarized ThreeDimensional Architecture Confers Resistance to Apoptosis in normal and Malignant Mammary Epithelium. Cancer Cell 2 (3), 205-216. doi:10.1016/ s1535-6108(02)00125-3

Wu, J., Gao, W., Tang, Q., Yu, Y., You, W., Wu, Z., et al. (2021). M2 MacrophageDerived Exosomes Facilitate HCC Metastasis by Transferring a M $\beta 2$ Integrin to Tumor Cells. Hepatology 73 (4), 1365-1380. doi:10.1002/hep.31432

Wu, X., Cai, J., Zuo, Z., and Li, J. (2019). Collagen Facilitates the Colorectal Cancer Stemness and Metastasis through an integrin/PI3K/AKT/Snail Signaling
Pathway. Biomed. Pharmacother. 114, 108708. doi:10.1016 j.biopha.2019.108708

Yamada, M., and Sekiguchi, K. (2015). Molecular Basis of Laminin-Integrin Interactions. Curr. Top. Membr. 76, 197-229. doi:10.1016/bs.ctm.2015.07.002

Yan, H., Zheng, C., Li, Z., Bao, B., Yang, B., Hou, K., et al. (2019). NPTX1 Promotes Metastasis via Integrin/FAK Signaling in Gastric Cancer. Cancer Manag. Res. 11, 3237-3251. doi:10.2147/CMAR.S196509

Yang, L., Zhang, L., Wu, Q., and Boyd, D. D. (2008). Unbiased Screening for Transcriptional Targets of ZKSCAN3 Identifies Integrin $\beta 4$ and Vascular Endothelial Growth Factor as Downstream Targets. J. Biol. Chem. 283 (50), 35295-35304. doi:10.1074/jbc.M806965200

Yang, M.-H., Zhao, L., Wang, L., Ou-Yang, W., Hu, S.-S., Li, W.-L., et al. (2019). Nuclear lncRNA HOXD-AS1 Suppresses Colorectal Carcinoma Growth and Metastasis via Inhibiting HOXD3-Induced Integrin $\beta 3$ Transcriptional Activating and MAPK/AKT Signalling. Mol. Cancer 18 (1), 31. doi:10.1186/ s12943-019-0955-9

Zaidel-Bar, R., Itzkovitz, S., Ma'ayan, A., Iyengar, R., and Geiger, B. (2007). Functional Atlas of the Integrin Adhesome. Nat. Cell Biol. 9 (8), 858-867. doi: $10.1038 /$ ncb0807-858

Zang, D., Zhang, C., Li, C., Fan, Y., Li, Z., Hou, K., et al. (2020). LPPR4 Promotes Peritoneal Metastasis via Sp1/integrin a/FAK Signaling in Gastric Cancer. Am. J. Cancer Res. 10 (3), 1026-1044.

Zhang, X., Zhang, C., Ren, Z., Zhang, F., Xu, J., Zhang, X., et al. (2020). Curcumin Affects Gastric Cancer Cell Migration, Invasion and Cytoskeletal Remodeling through Gli1$\beta$-Catenin. Cancer Manag. Res. 12, 3795-3806. doi:10.2147/CMAR.S244384

Zhao, Y., Nakagawa, T., Itoh, S., Inamori, K.-i., Isaji, T., Kariya, Y., et al. (2006). $\mathrm{N}$-acetylglucosaminyltransferase III Antagonizes the Effect of $\mathrm{N}$-Acetylglucosaminyltransferase $\mathrm{V}$ on $\alpha 3 \beta 1$ Integrin-Mediated Cell Migration. J. Biol. Chem. 281 (43), 32122-32130. doi:10.1074/jbc.M607274200

Zhou, B., Zong, S., Zhong, W., Tian, Y., Wang, L., Zhang, Q., et al. (2020). Interaction between Laminin-5 $\gamma_{2}$ and Integrin $\beta 1$ Promotes the Tumor Budding of Colorectal Cancer via the Activation of Yes-Associated Proteins. Oncogene 39 (7), 1527-1542. doi:10.1038/s41388-019-1082-1

Zhou, X., Shan, Z., Yang, H., Xu, J., Li, W., and Guo, F. (2018). RelB Plays an Oncogenic Role and Conveys Chemo-Resistance to DLD-1 Colon Cancer Cells. Cancer Cell Int. 18, 181. doi:10.1186/s12935-018-0677-x

Conflict of Interest: The authors declare that the research was conducted in the absence of any commercial or financial relationships that could be construed as a potential conflict of interest.

Publisher's Note: All claims expressed in this article are solely those of the authors and do not necessarily represent those of their affiliated organizations, or those of the publisher, the editors and the reviewers. Any product that may be evaluated in this article, or claim that may be made by its manufacturer, is not guaranteed or endorsed by the publisher.

Copyright (c) 2021 Hou, Wang, Li, Hao and Hang. This is an open-access article distributed under the terms of the Creative Commons Attribution License (CC BY). The use, distribution or reproduction in other forums is permitted, provided the original author(s) and the copyright owner(s) are credited and that the original publication in this journal is cited, in accordance with accepted academic practice. No use, distribution or reproduction is permitted which does not comply with these terms. 